\section{Dissertações e teses do Programa de Pós- Graduação Stricto Sensu em Ciências da Saúde da Faculdade de Medicina do $A B C$}

\section{Teses de Doutorado}

RISCO DE DOENÇA CARDIOVASCULAR EM ÁRBITROS DE FUTEBOL DE CAMPO

Autor: Marcelo Ferreira

Orientadores: Prof. Dr. Luiz Carlos de Abreu e Prof. Dr. João Roherto Breda Defesa de Tese: 15/07/2011

Introdução: A taxa de mortalidade dentre os futebolistas, embora baixa, causa enorme impacto em toda comunidade e constitui um grande enigma. Objetivos: estudar o risco cardiovascular de árbitros de grande performance no futebol; descrever a frequência de risco cardiovascular considerando grupos etário grande performance no futebol; descrever a frequência de risco cardiovascular considerando grupos etários
menores e maiores do que 35 anos de idade; relacionar os índices de Framingham e de PROCAM na menores e maiores do que 35 anos de idade; relacionar os índices de Framingham e de PROCAM na comparação do risco cardiovascular de árbitros de futebol. Método: cinquenta árbitros de alta performance
da Federação Paulista de Futebol foram submetidos a avaliações clínicas e laboratoriais no Núcleo de da Federação Paulista de Futebol foram submetidos a avaliações clínicas e laboratoriais no Núcleo de
Saúde no Esporte da Faculdade de Medicina do ABC e divididos em dois grupos: menor e maior de 35 anos de idade. Foi realizada a análise descritiva do grupo inteiro, a seguir considerada a avaliação bidimensional e posteriormente aplicados os métodos de Framingham e o de PROCAM. Finalmente procedeu-se análise por regressãologistica. Resultados: os valores antropométricos, de pressão arterial, das variáveis bioquímicas e ergoespirométricas apresentaram-se dentro dos padrões de normalidade. Conclusões: escore de Framingham se mostrou um bom marcador para fatores de risco com relação à idade e mais fiel do que o escore PROCAM; o risco para coronariopatias foi estatisticamente superior nos árbitros com idades superiores a 35 anos; a exposição dos árbitros a outras causas de cardiopatia não diferiu significantemente em relação aos grupos com idades acima e abaixo de 35 anos.

ESTUDO DA INFLUÊNCIA DA CONTRACEPÇ̃̃O HORMONAL

ORAL COMBINADA CONTENDO ETINILESTRADIOL E LEVONORGESTREL SOBRE O PERFIL LIPÍDICO E LIPOPROTEICO E A SUA INTER-RELAÇÃO COM A FUNÇÃO SEXUAL FEMININA

Autor: Rodolfo Strufaldi

Orientador: Prof. Dr. Cesar Eduardo Fernandes

Defesa de Tese: $12 / 12 / 2011$

Introdução: A influência da contracepção hormonal oral sobre a função sexual feminina apresenta lacunas de conhecimento, particularmente com respeito ao papel exercido sobre o perfil lipídico e a sua inter-relação. Objetivo: Avaliar o efeito da formulação contraceptiva contendo Etinilestradiol (EE) e Levonorgestrel (LNG) sobre o perfil Avaliar o efeito da formulação contraceptiva contendo Etinilestradiol (EE) e Levonorgestrel (LNG) sobre o perfín
lipídico e lipoproteico e a inter-relação com a função sexual feminina. Métodos: Estudo prospectivo, aberto randomizado, conduzido no Centro de Planejamento Familiar da Faculdade de Medicina do ABC, avaliou 51 mulheres saudáveis mulheres saúáveis sem manifestação na anamnese de disfunção sexual, com média etária de 29,4 anos, as quais medicaço foi administrada em ciclos de 21 dias com pausa de 7 dias, (urante seis ciclos consecutivos. A amostra de medicação foi administrada em ciclos de 21 dias, com pausa de 7 dias, durante seis ciclos consecutivos. A amostra de (LDL $>130 \mathrm{mg} / \mathrm{dL}$ ), sendo comparadas com uma população de mesma faixa etária e com as mesmas características ( $\mathrm{LDL}>130 \mathrm{mg} / \mathrm{dL}$ ), sendo comparadas com uma população de mesma faixa etária e com as mesmas características
sem alteração lipídica e lipoproteica ( $\mathrm{LDL}<130 \mathrm{mg} / \mathrm{dL}$ ). Todos os parâmetros lipídicos e lipoproteicos foram sem alteração lipídica e lipoproteica (LDL $<130 \mathrm{mg} / \mathrm{dL}$ ). Todos os parâmetros lipídicos e lipoproteicos foran
avaliados no início e após o sexto ciclo de tratamento. Os domínios da função sexual feminina foram avaliado avaliados no início e após o sexto ciclo de tratamento. Os domínios da função sexual feminina foram avaliados fazendo-se uso de um questionário padronizado [índice de Função Sexual Feminino (FSFI)] no início e ao final de seis meses do período de observação. Resultados: Das cinquenta e uma mulheres usuárias da formulação contraceptiva que foram incluídas, 49 mulheres conclúram o estudo. Apenas o grupo de pacientes com LDL $>130$ apresentou redução estatisticamente significante nos níveis de colesterol total e de LDL, sendo a redução percentual média de 14,7 e 22,1\% respectivamente. Quanto à avaliação sexual, ambos os grupos estudados mostraram melhora estatisticamente significante no escore total, e nos domínios excitação e orgasmo. Os domínios desejo satisfação apresentaram melhora estatisticamente significante apenas no grupo que não apresentava alterações no domínios de lubrificação, orgasmo e escore total da função sexual feminina. Após o teste de regressão múltipla, o

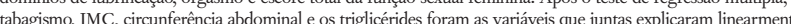
$46,0 \%$ lo 46, o do escore total do Fun colesterol total e LDL apenas no grupo que os valores estavam alterados no início do estudo. Houve correlaçãa positiva entre o HDL com os domínios de lubrificação, orgasmo e escore total no final do estudo.
0 VECTORCARDIOGRAMA DO PADRÃO BRUGADA TIPO 1: ESTUDO COMPARATIVO COM VECTORCARDIOGRAMAS DE SUJEITOS HÍGIDOS PORTADORES DE BLOQUEIO INCOMPLETO E COMPLETO DO RAMO DIREITO

Autor: Andrés Ricardo Pérez Riera

Drientador Prof. Dr. Celso Ferreir

Defesa de Tese: 11/05/2011

Fundamento: A síndrome de Brugada é una canalopatia hereditária autossômica dominante sem cardiopatia estrutural aparente, com variada tendência a morte súbita arrítmica e eletrocardiograma característico: elevação estrutural aparente, com variada tendência a morte súbita arrítmica e eletrocardiograma característico: elevação
do ponto J e segmento $\mathrm{ST} \sim 2 \mathrm{~mm}$ em precordiais direitas de $\mathrm{Vl}$ a V2 ou de $\mathrm{Vl}-\mathrm{V} 3$ seguido de onda T negativa (padrão tipo 1) e eventual presença de bloqueio do ramo direito incompleto (BIRD) o completo (BCRD) frequentemente atípicos. Objetivos: Comparar os vetorcardiogramas (VCGs) empregando o método de Frank (F-VCGs) de pacientes Brugada sintomáticos com padrão ECG tipo 1 com os F-VCGs de indivíduo aparentemente hígidos sem cardiopatia estrutural e com BIRD e BCRD em seus ECGsNCGs. Métodos: Comparamos três grupos I, II e III sendo os grupos II e III os controles: Grupo I (n=11): F-VCGs de 1 pacientes Brugada com o padrão ECGNCG tipo 1. Grupo II $(\mathrm{n}=20)$ : F-VCGs de indivíduos sem aparente cardiopatia estrutural com padrão BIRD em seus ECGsNCGs. Grupo III ( $\mathrm{n}=12$ ): F-VCGs de indivíduos sem aparente cardiopatia estrutural com BCRD. Resultados: Vetor dos 10 a $20 \mathrm{~ms}$ iniciais da alça QRS no plano horizontal (PH): Grupos I e II dirigido para frente e a esquerda. No grupo III para frente e à direita. Localização do atraso final de condução (AFC) Grupo I: no quadrante superior direito no plano frontal (PF) e no quadrante posterior direito no PH. Grupo II: localizado no quadrante inferior direito em sete casos (35\%) no PF e no posterior direito no PH. Grupo III: todos localizados no quadrante anterior direito no PH. Pontos O (início da alça QRS) e J (fim da alça QRS): Grupo I: não coincidentes e nos Grupos II e III coincidentes. Aspecto e morfologia da alça T: Grupo I: pequena, circular, arredondada e de ramos simétricos em 10 casos ( $90 \%$ ). Grupos II e III: ramo eferente é de inscrição mais lenta do que o aferente e elíptica. Conclusão: O F-VCG de pacientes Brugada com padrão ECG tipo 1 mostrou características diferentes do que o F-VCG de indivíduos sem aparente cardiopatia estrutural com BIRD ou BCRD. O F-VCG pode ajudar no diagnóstico da síndrome de Brugada.

EXPRESSÃO DA HEPARANASE DURANTE 0

REMODELAMENTO DA MATRIZ EXTRACELULAR NA DEGENERAÇÃO DO DISCO INTERVERTEBRAL

Autor: Luciano Miller Reis Rodrigues

Orientadora: Profa. Dra. Maria Aparecida da Silva Pinha

Defesa de Tese: $07 / 12 / 2011$

A dor lombar é uma das afecções musculoesqueléticas mais comuns na população em geral. Sua etiologia é multifatorial e pode ser causada por doenças inflamatórias, neoplásicas, defeitos congênitos, debilidade muscular, predisposição reumática ou sinais de degeneração da coluna ou dos discos intervertebrais. A degeneração do disco intervertebral tem sido apontada como a principal causa de dor lombar. Durante o processo degenerativo do disco intervertebral o paciente pode sentir dor, resultante da inflamação das estruturas degeneradas ou da compressão sobre as estruturas nervosas devido à instabilidade. A principal alteração molecular na degeneração do disco intervertebral é caracterizada pela perda progressiva de proteoglicanos. A redução desse conteúdo leva à redução na retenção de água, ocasionando diminuiç̃ão na capacidade do disco de amortecimento durante pressões mecânicas. Enzimas proteolíticas que fragmentam os proteoglicanos podem, ainda induzir ou inibir as respostas mecânicas. Enzimas proteoliticas que fragmentam os proteoglicanos podem, ainda, induzir ou inibir as respostas é uma importante enzima proteolítica, que degrada cadeias de heparam sulfato (HS) e proteoglicanos de heparam sulfato (PGHS) da superfície celular e da matriz extracelular, liberando oligossacarídeos com maior afinidade por fatores angiogênicos, um mecanismo extremamente importante no processo inflamatório e no remodelamento fatores angiogênicos, um mecanismo extremamente importante no processo inflamatório e no remodelamento
de matriz extracelular. Porém, a expressão desta enzima em discos intervertebrais degenerados ainda não foi de matriz extracelular. Porém, a expressão desta enzima em discos intervertebrais degenerados ainda não foi
avaliada. Visto que a fisiopatologia da degeneração discal envolve um mecanismo de inflamação que pode ser avaliada. Visto que a fisiopatologia da degeneração discal envolve um mecanismo de inflamação que pode ser desencadeado por alterações moleculares na matriz extracelular, e que os fragmentos de HS, gerados pela ação d heparanase sobre os PGHS, estão amplamente relacionados com aumento de vascularização e inflamação, tivenos o interesse em estudar a expressão desta enzima em discos intervertebrais degenerados e não degenerados e analisa seu envolvimento no desenvolvimento da degeneração do disco intervertebral. Também tivemos o interesse de estudar outras moléculas envolvidas no processo inflamatório da degeneração discal, como a interleucina-6 (IL-6), a catepsina $\mathrm{B}$ e o ácido hialurônico (AH). Os resultados evidenciaram as alterações das isoformas de heparanase (HPSE1 e HPSE2), e dos mediadores IL-6, AH e catepsina B no processo de remodelamento da matriz extracelula durante a degeneração do disco intervertebral. Tais resultados poderão contribuir para estudos mais avançados que ou outras formas de diagnóstico/prognóstico do processo de degeneração do disco intervertebral.

EFEITOS DA INIBIÇÃO DA CATALASE NO QUARTO VENTRÍCULO CEREBRAL NO REFLEXO DE BEZOLD-JARISCH EM RATOS ESPONTANEAMENTE HIPERTENSOS

Autor: José Raul Cisternas Gajardo

Orientadores: Prof. Dr. Luiz Carlos de Abreu e Prof. Dr. Victor Engrácia Valenti Defesa de Tese: $12 / 12 / 2011$

Muitos estudos têm investigado o papel do estresse oxidativo no sistema cardiovascular no tronco ncefálico de ratos espontaneamente (REH) Entretanto, ainda não sabemos se a inibição da catalase influencia o reflexo de Bezold-Jarisch (reflexo de Bezold-Jarisch). Assim, nosso foco foi avaliar os efeito da inibição central da catalase no reflexo de Bezold-Jarisch em REH. Ratos Wistar Kyoto (WKY) e REH foram implantados com cânula guia de aço inoxidável no quarto ventrículo cerebral $\left(4^{\circ} \mathrm{V}\right)$. Artéria femoral e veia femoral foram canuladas para determinação de pressão arterial média (PAM) e frequência cardíaca (FC) e infusão de drogas, respetivamente. O reflexo cardiopumonar foi testado com fenilbiguanida (PBG, $9 \mathrm{ug} / \mathrm{kg}$, em bolus, iv). O reflexo de Bezold-Jarisch foi avaliado antes e 15 minutos após administração de 3-amino-1,2,4-triazole (3-AT, $0.01 \mathrm{~g} / 100 \sim \mathrm{L}$ ) no $40 \mathrm{~V}$. O tratamento com veículo não mudou a PAM e a FC basais nos grupos REH e WKY. O 3-AT central intensificou a hipotensão $(\mathrm{p}=0,038)$ sem afetar a bradicardia reflexa $(\mathrm{p}=0,287)$ em ratos WKY. No grupo REH o 3-AT central aumentou tanto a hipotensão $(\mathrm{p}=0,0004)$ como a bradicardia $(\mathrm{p}=0,04)$. Não foram observadas alterações em relação a PAM e FC basais após a injeção de 3-AT nos grupos REH e WKY. Sugerimos que a inibição da catalase central afeta o reflexo de Bezold-Jarisch com mais intensidade em REH comparados com ratos WKY. 
ANASTOMOSE ESOFAGOGÁSTRICA CERVICAL COM INVAGINACCÃO DO COTO ESOFÁGICO PROXIMAL NO INTERIOR DO ESTÔMAGO APÓS ESOFAGECTOMIA POR CARCINOMA DO ESÔFAGO OU MEGAESÔFAGO AVANÇADO

Autor: Alexandre Cru₹ Henriques

Orientador: Prof. Dr. Jaques Waisberg Defesa de Tese: 16/12/2011

Introdução: A fístula da anastomose esofagogástrica cervical permanece como um dos principais desafio das esofagectomias. Objetivo: Avaliar a incidência de fístula e estenose da anastomose esofagogástric cervical com invaginação do coto esofágico proximal no interior do estômago após esofagectomia subtotal. Método: Foram estudados 54 doentes submetidos à esofagectomia subtotal, 45 (83,3\%) com carcinom e $9(16,6 \%)$ com megaesôfago chagásico avançado. Em todos os casos, a anastomose esofagogástrica cervical foi realizada com invaginação do coto esofágico proximal no interior do estômago. Resultados: Três $(5,5 \%)$ doentes apresentaram fístula, 2 deles com saída mínima de ar e saliva pela incisão cervical que evoluíram com rápida cicatrização; o terceiro apresentou fístula de pequeno débito que drenou

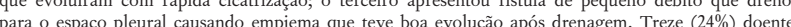
para o espaço pleural causando empiema que teve boa evoluçáo após drenagem. Treze (24\%) doentes a reso (n) proxim encontrados na literatura, tomando-se opção atraente para a reconstruç̃o do trânsito alimentar após esofagectomia subtotal.
ESTUDO DE POLIMORFISMOS DO GENE DO RECEPTOR DA VITAMINA D EM MULHER INFÉRTEIS COM E SEM ENDOMETRIOSE

Autora: Fabia Lima Vilarino

Orientador: Prof. Dr. Caio Parente Barbosa

Defesa de Tese: 17/01/2012

Um mecanismo imunológico aberrante tem sido sugerido envolvendo a patogênese da endometriose. Alterações genéticas do gene do receptor da vitamina $\mathrm{D}(V D R)$ podem levar a um defeito na ativação gênica que afeta principalmente a função imune. Nós hipotetizamos uma possível relação entre endometriose e/ou a infertilidade e os polimorfismos VDR (ApaI, TaqI, FokI, e BmsI). Estudo casocontrole incluindo 132 mulheres com endometriose relacionada à endometriose, 62 mulheres con infertilidade sem causa aparente e 133 controles. Polimorfismos $V D R$ foram estudados por polimorfismo de fragmentos de restriç̃o. Não encontramos diferença siơnificativamente siơnificante nas frequêncios dos polimorfismos entre o caso e o controle. Quando estudamos separadamente as pacientes com endom

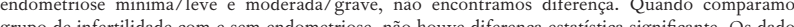
sugerem que os polimorfismos VDR não tem envolvimento importante na patogênese da endometriose sugerem que os polimorfismos VDR não tem envolvi

\section{Dissertações de Mestrado}

\section{MARCADORES BIOQUÍMICOS DO METABOLISMO ÓSSEO E DENSIDADE MINERAL ÓSSEA EM MULHERES SUBMETIDAS À CIRURGIA BARIÁTRICA}

\section{Autor: Maria Tereza Amaral dos Santos}

Orientadora: Profa. Dra. Roseli Oselka Saccardo Sarni Defesa da Dissertação: 01/10/2010

Introdução: A deficiência do cálcio e alterações no metabolismo ósseo tem sido relatada em pacientes submetidos ao Bypass gástrico em Y de Roux (RYGB). O hiperparatireoidismo descrito nestes pacientes pode ocasionar redução da densidade mineral óssea levando a complicações como osteoporose. Os estudo disponíveis, a maioria retrospectivos, mostram resultados controversos. Objetivo: Avaliar os marcadore bioquímicos relacionados ao metabolismo ósseo e a densidade mineral óssea (DMO) de mulheres adultas submetidos à cirurgia bariátrica (RYGB). Método: Por meio de estudo transversal e prospectivo foram avaliadas 49 mulheres submetidas ao RYGB e 42 mulheres saudáveis de mesma idade e condição econômica (controle). Foram coletados, utilizando-se questionário padronizado e pré-codificado, parâmetros clínicos e antecedentes. Foram avaliados: índice de Massa Corporal (OMS 2005), O nível de atividade física (IPAC, versão curta), consumo alimentar (registro de quatro dias, Nut Win/Unifesp). Níveis séricos de cálcio fósforo, magnésio, fosfatase alcalina, C-telopeptídeo (CTX), paratormônio intacto (PTHi), 25 hidrosi fosforo, magnésio, fosfatase alcalina, C-telopeptídeo (CTX), paratormônio intacto (PTHi), 25 hidrox colecalciferol $(250 \mathrm{H}$ vitamina D), osteocalcina, cálcio urinário e albumina e a densidade mineral ósse (DMO) por absorciometria por dupla emissão de feixes de raios X (DXA-QDR 1000 Hologic). Anális estatística: teste de Mann-Whitney, $\chi 2$ e correlação de Spearman. Adotou-se nível de significância de $5 \%$. Resultados: Em relação ao IMC, diferença significante entre os grupos, mediana 31,1 e $25,6 \mathrm{~kg} /$ $\mathrm{m}^{2}$ para casos e controles, respectivamente $(\mathrm{p}<0,001)$. Observou-se maior percentual de inadequação para osteocalcina $(68,7$ e 19,1\%; $<<0,001)$, CTX (33,3 e 2,4\%; $<0,001)$ e PTHi (41,7 e 4,8\%; $<0,001)$ no grupo RYGB comparativamente ao controle. A mediana dos níveis de 25(OH)D diferiu de form estatisticamente significante entre os grupos $(\mathrm{p}<0,001)$, a deficiência $(<20 \mathrm{ng} / \mathrm{mL})$ foi observada em 56 , e 20,5\% dos grupos RYGB e controles, respectivamente. Observou-se correlação inversa e significativ entre níveis de PTH intacto e 25(OH)D $(r=-0,57 ; \mathrm{p}<0,05)$. Não houve diferença estatisticamente significante no comprometimento de massa óssea e no consumo de cálcio entre os grupos RYGB e controle. Conclusão: Pacientes submetidas RYGB apresentaram maior frequência de deficiência de vitamina D, hiperparatiroidismo secundário e remodelação óssea intensa com risco aumentado para doenças ósseas.

\section{AVALIAÇÃO DOS PARÂMETROS CARDIOVASCULARES E ESTRESSE OXIDATIVO PROMOVIDOS PELO EXERCÍCIO RESISTIDO EM HUMANOS}

Autor: Fabiana Reis

Orientadora: Profa. Dra. Monica Akemi Sato

Defesa da Dissertação: 05/11/2010

Introdução: Atualmente há uma grande incidência de pessoas com problemas cardiovasculares. E dentro deste contexto a prática do exercício físico parece provocar adaptações sobre o sistema cardiovascular. O exercício físico pode auxiliar no controle da pressão arterial e nos valores da frequência cardíaca, induzindo a uma maior atividade parassimpática em repouso. Algumas pesquisas mostram também, que o exercício físico pode aumentar os níveis séricos da enzima paraoxonase, esta que age como um mecanismo de defesa antioxidante. Objetivos: Analisar as respostas cardiovasculares induzidas por uma mécanismo de defesa antioxidante. Objetivos: Analisar as respostas cardiovasculares induzidas por uma unica sessão de exercícios resistidos e a inflénciá do exercício fisico sobre o balanço entre pró-oxidantes e antioxidantes. Materiais e Métodos: 64 voluntários foram divididos em 2 grupos: sedentários e treinados. Foram submetidos a uma unica sessão de exercício resistido a $65 \%$ de 1 RM com 3 séries de 12 repetições. Foram mensuradas a pressão arterial e a frequência cardíaca em repouso, imediatamente após o término do exercício, 30 minutos após e 60 minutos após. A atividade sérica da PONl foi avaliada no repouso e
imediatamente após o exercício. Resultados: O grupo treinado apresentou valores da pressão arterial mais imediatamente após o exercício. Resultados: O grupo treinado apresentou valores da pressão arterial mais da PON1 o grupo treinado apresentou maior atividade após a sessão de exercicio resistido, mesmo com os valores do colesterol não apresentando diferenças significativas. Conclusão: Os resultados sugerem que o grupo treinado parece ter a sensibilidade barorreflexa aumentada quando comparado ao grupo sedentário a, parece também haver uma adaptação maior ou mais eficiente do sistema antioxidante.

\section{ESTUDO DA EXPRESSÃO DE ISOFORMAS DA ENZIMA HEPARANASE EM CARCINOMA RENAL}

Autor: Sabrina do Nascimento

Orientadora: Profa. Dra. Maria Aparecida da Silva Pinhal

Defesa da Dissertação: 08/10/2010

Introdução: Nos últimos dez anos foram desenvolvidas novas técnicas minimamente invasivas, oferecendo alternativas para a cirurgia convencional e reduzindo a morbidade e mortalidade dos pacientes com carcinoma de células renais, entretanto, não existem atualmente marcadores de diagnóstico, precoce e tratamento atuais para tal doença. Portanto, a investigação de componentes da matriz extracelular pode elucidar alterações que contribuam em encontrar molécula para o diagnóstico, prognóstico ou como alvo para o traçoes que contribuam em encontrar molécula para o diagnóstico, prognóstico ou como alvo para o tratamento deste tipo de câncer. Estudos prévios de nosso grupo evidenciaram aumento da não acometidos por neoplasia. A expressão da heparanase-1 (HPA 1) encontra-se significativamente não acometidos por neoplasia. A expressão da heparanase-1 (HPA I) encontra-se significativamente
aumentada em carcinoma renal quando comparado com o grupo controle ( $\mathrm{p}=0,027)$ por análises aumentada em carcinoma renal quando comparado com o grupo controle $(\mathrm{P}=0,027)$ por analise realizadas em tempo real e todos os tecidos acometidos apresentavam aumento da expressão. A
investigação semiquantitativa demonstrou que apenas $50 \%$ dos casos apresentava aumento na expressão investigação semiquantitativa demonstrou que apenas $50 \%$ dos casos apresentava aumento na expressão
da HPA 1 e o grupo controle não mostrou expressão de tal enzima. A avaliação da expressão da HPA2 por amplificação do RNA mensageiro por tempo real demonstrou que esta isoforma não represent significativa de expressão entre os tecidos com carcinoma renal e grupo controle. Estes resultados revelaram que a avaliação por tempo real é muito mais sensível e precisa quando comparada com a técnica semiquantitativa e que HPA 1 e sugerem que HPA 1 possivelmente poderá ser utilizada como um potencial marcador para o diagnóstico de carcinoma renal.

\section{URTICÁRIA: AVALIAÇÃO CLÍNICA, LABORATORIAL E TERAPÊUTICA EM 108 PACIENTES}

Autora: Jussara Joana de Medeiros Cavalcante Carneiro

Orientadores: Profa. Dra. Maria Aparecida da Silva Pinhal e Prof. Dr. Carlos D’Apparecida S. Machado Filho

Defesa da Dissertação: 22/11/2010

Fundamentos: A urticária é uma das doenças da pele mais comuns, porém a sua etiopatogenia e a sua relação com a autoimunidade são ainda bastante discutidas. Objetivo: Descrever as características clínicas, laboratoriais e terapêuticas de pacientes com urticária. Casuística e Métodos: Estudo retrospectivo
$\mathrm{em}$ instituição de atendimento de nível terciário em que foram revisados 108 prontuários. Resultados: em instituição de atendimento de nível terciário em que foram revisados 108 prontuários. Resultados:
$79 \%$ eram mulheres e a idade média foi de 44 anos. Apenas 2 pacientes apresentaram a forma aguda da doença. Dos 106 restantes, $56 \%$ apresentaram sintomas com duração até 3 anos. $35 \%$ dos paciente referiram antecedente de atopia e 53\% a ocorrência de angioedema. A Imunoglobulina E se mostro alterada em $31 \%$ dos pacientes. O fator antinuclear e o fator reumatoide foram positivos em 21 e $15 \%$ dos casos, respectivamente, e os anticorpos antitireoidianos em $10 \%$. Houve aumento na velocidade de hemossedimentação em 46\% (31/68) e da proteína C reativa em 23\% (19/84) dos pacientes examinados. O teste do autossoro foi realizado em 58 pacientes com urticária crônica dos quais 50 \% foi positivo e não houve associação estatistica com os exames laboratoriais. Os antihistamínicos $\mathrm{Hl}$ (anti H1) de segunda geração foram efetivos para controlar mais da metade dos casos como monoterapia em dose padrão e apenas $13 \%$ dos casos necessitou do uso de outras drogas adjuvantes. Conclusão: Os achados clínicos e laboratoriais foram compatíveis com a literatura, porém a resposta ao tratamento foi surpreendente com anti $\mathrm{Hl}$ de segunda geração como monoterapia. 


\section{FATORES PREDITIVOS PARA INDICAÇÃO DE LITOTRIPSIA} DURANTE URETEROSCOPIA

Autor: Antonio Corrêa Lopes Neto

Orientador: Prof. Dr. Antonio Carlos Lima Pompeo

Defesa da Dissertação: 08/12/2010

Objetivos: $\mathrm{O}$ objetivo deste estudo foi avaliar os dados de ureteroscopia (URS) realizada para tratamento $\mathrm{d}$ litíase ureteral (LU) e determinar se as dimensões e a topografia do cálculo podem predizer a necessidade de litotripsia intracorporea (LIGO) durante o procedimento, e assim auxiliar no planejamento pré-operatório. Outras análises adicionais serão realizadas visando correlacionar dimensões do cálculo e resultados d URS. Pacientes e Método: Foram envolvidos prospectivamente 214 pacientes submetidos à URS par tratamento de LU. Todos os cálculos não haviam sido manipulados previamente e eram visíveis ao raio $\mathrm{X}$ de abdome. Por meio de estudo radiológico, foi determinada a localização dos cálculos e suas dimensões. Utilizando o raio X, o tamanho do cálculo foi mensurado considerando o maior diâmetro $(\mathrm{mm})$ e sua área fö determinada multiplicando-se os dois maiores eixos do cálculo (mm2). Durante o procedimento, os ć́lub determinad, foram extraidos intactos ou após fragmentação. A indicação de LICO foi analisada baseado nas dimensões localização do cálculo. Análises adicionais foram realizadas estratificando pacientes considerando tamanho (UD) 20,6 . Resultados: Em relação à localização dos cálculos, $67,3 \%$ se localizavam no ureter dista (UD), 20,6\% no ureter proximal (UP) e 12,1\% no ureter médio (UM). LlCO foi necessária em $60,3 \%$ do tota dos procedimentos. Considerando a localização, os cáculos em UP, UM e UD necessitaram fragmentação 年 $4,8 \%, 47.1,67,4$ e $83,3 \%$ para cálculos s $20 \mathrm{~mm}^{2},>20-40 \mathrm{~mm}^{2},>40-60 \mathrm{~mm}^{2}$ e $>60 \mathrm{~mm}^{2}$, respectivamente.
Analisando achados adicionais, a taxa de sucesso diminuiu com o aumento da área do cálculo ( $\mathrm{p}<0,021$ ). Não Analisando achados adicionais, a taxa de sucesso diminuiu com o aumento da área do cálculo $(\mathrm{p}<0,021)$. Não
houve diferença estatística no sucesso da URS, considerando apenas a estratificação por tamanho $(\mathrm{mm})$ do cálculos. Conclusões: Durante ureteroscopia para litíase ureteral, litotripsia intracorpórea é necessária n maioria dos cálculos em ureter proximal e médio, e quando as dimensões são maiores que $20 \mathrm{~mm}^{2}$. Para estes pacientes, os procedimentos são mais prolongados, complexos e a necessidade de colocação de cateter duplo Jé maior. Entretanto não ocorre interferência significativa nas taxas de sucesso. A análise comparativa entre tamanho e área do cálculo mostra que este último parâmetro é mais acurado para determinar a taxa de sucesso. Existe uma relação entre cálculos com áreas maiores e piores resultados.

\section{ANÁLISE DO PERFIL DA MORTALIDADE MATERNA NA REGIÃO DO GRANDE ABC}

Autora: Silvana Tognini

Orientadora: Prof Dra. Lourdes Conceição Martins

Defesa da Dissertação: 20/12/2010

Introdução: A mortalidade materna é um bom indicador da realidade socioeconômica de um país e da qualidade de vida de sua população. Objetivo: Comparar o coeficiente de mortalidade materna obtido pelo qualidade de vida de sua população. Objetivo: Comparar o coeficiente de mortalidade materna obtido pel Saúde 11 de Santo André (DI R 11), com o coeficiente de mortalidade materno fornecido pela Fundação Saúde 11 de Santo André (DI R 11), com o coeficiente de mortalidade materno fornecido pela Fundação causas de óbitos maternos. Casuística e Métodos: Este é um estudo transversal. As informaç̃ôes foram causas de óbitos maternos. Casuistica e Métodos: Este é um estudo transversal. As informações foram obtidas junto ao banco de dados do CEMM da DIR 11 - Santo André, que compreende a participação dos sete Municípios da Região do Grande ABC que são: Santo André, São Bernardo do Campo, São Caetano
do Sul, Diadema, Mauá, Ribeirão Pires e Rio Grande da Serra e os conselhos de classe da Enfermagem e do Sul, Diadema, Mauá, Ribeirão Pires e Rio Grande da Serra e os conselhos de classe da Enfermagem e de Medicina do Estado de São Paulo. Foram analisados todos os óbitos de mulheres (população feminina)
em idade fértil (de 10 a 49 anos) ocorridos no período de 1997 a 2005 na Região do Grande ABC. Os testes pareado, Wilcoxon e Kruskal-Wallis foram utilizados para a análise estatística. Resultados: Pelo teste

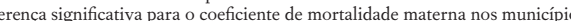
de Diadema, São Bernardo do Campo, Santo André e DIR2, onde temos que os maiores coeficientes de mortalidade materna são observados pelo CEMM do que pelo SEADE $(\mathrm{p}<0,001)$. Já para os municípios de Mauá, Rio Grande da Serra, Ribeirão Pires e São Caetano do Sul não foram observadas diferença significativas entre esses dois coeficientes $(\mathrm{p}>0,05)$, apesar de que o coeficiente de mortalidade matern obtido pelo CEMM é sempre maior do que o coeficiente de mortalidade materna obtido pelo SEADE. Conclusão: Conhecer a história da mortalidade materna deveria despertar nas autoridades competentes a consciência desta situação, para que fosse priorizado o atendimento integralizado à saúde da mulher e ainda alertar a população para a exigência de um atendimento efetivo para a promoção da saúde e a diminuição dos índices de mortalidade

\section{QUALIDADE DE VIDA DOS PACIENTES PORTADORES DE HIPERTENSÃO ARTERIAL SISTÊMICA ACOMPANHADOS EM UM SERVIÇO DE ESPECIALIDADE EM SANTO ANDRÉ}

Autor: Margarita Del Salvador Beatove

Orientadora: Profa. Dra. Lourdes Conceição Martins

Defesa da Dissertação: 20/01/2011

Introdução: A hipertensão arterial é uma doença crônico-degenerativa de natureza multifatorial, na grande maioria dos casos assintomática, que ocasiona danos nos órgãos nobres, como olhos, coração, rins e cérebro, Apresenta elevada morbimortalidade, portanto, um importante problema de Saúde pública. Objetivo: Avaliar a qualidade de vida dos pacientes portadores de hipertensão arterial sistêmica acompanhados em um serviço de especialidade em Santo André. Casuística e Métodos: Foram entrevistados 71 pacientes hipertensos, com idade acima de 40 anos atendidos no ambulatório de HAS da FMABC. Foram utilizados dois questionários um versava sobre informações sociobiodemográficas, e o outro foi o questionário já dois questionarios um versava sobre informaçoes sociobiodemograficas, e o outro foi o questionarió já vescritiva, teste de $\chi^{2}$, teste de comparação entre duas proporções, teste U de Mann-Whitney, correlação de Pearson e análise de regressão linear. Resultados: Em relação ao perfil biodemográfico a maioria dos pacientes apresentava estado civil casado, baixo nível de instrução, moradia própria, sem função dos pacientes apresentava estado civil casado, baixo nivel de instrução, moradia propria, sem função a utilização prévia ou atual de medidas não farmacológicas. Os pacientes que praticam atividade física apresentaram melhor qualidade de vida $(\mathrm{p}<0,05)$. Com relação aos domínios do questionário de qualidade de vida MINICHAL, observamos correlação significativa entre estado mental e manifestações somática $(\mathrm{r}=0,73, \mathrm{p}<0,001)$, estado mental e influência na vida $(\mathrm{r}=0,50, \mathrm{p}<0,001)$, e entre manifestações somática e influência na vida $(r=0,54, p<0,001)$. Conclusão: A realização de atividade física melhora a qualidade de vida de pacientes hipertensos.

\section{QUALIDADE DE VIDA E ADESÃO AO TRATAMENTO FARMACOLÓGICO DOS PACIENTES COM HIPERTENSÃO ARTERIAL SISTÊMICA QUE UTILIZAM A FARMÁCIA-ESCOLA DA UNIVERSIDADE MUNICIPAL DE SÃO CAETANO DO SUL}

Autora: Cicera Cristina Vidal Aragão Orientadora: Profa. Dra. Lourdes Conceição Martins Defesa da Dissertação: 20/12/2010

Introdução: A hipertensão arterial sistêmica (HAS) é reconhecida como principal fator de risco para doença cerebrovascular, doença arterial coronariana, insuficiência renal crônica e doença vascular de extremidades. A não adesão ao tratamento anti-hipertensivo aumenta o risco de eventos adversos e pode acarretar uma pior qualidade de vida. Objetivo: Avaliar a qualidade de vida e o nível de adesão o tratamento farmacológico de pacientes portadores de hipertensão arterial, usuários de uma farmáci escola. Casuística: Este é um estudo transversal, realizado através da aplicação de três questionários: o questionário de Morisky \& Green para verificar a adesão ao tratamento medicamentoso, o questionário questionário de Morisky \& Green para verificar a adesão ao tratamento medicamentoso, o questionário
de qualidade de vida em hipertensão arterial (MINICHAL-BRASIL), e o questionário de dados de qualidade de vida em hipertensão arterial (MINICHAL-BRASIL), e o questionário de dados biodemográficos para o período de outubro de 2009 a agosto de 2010. Foi realizada a análise descritiva
de todas as variáveis, e os testes de $\chi 2$ e U de Mann-Whitney. Resultados: Participaram do estudo 190 pessoas, sendo $81(42,6 \%)$ homens e $109(57,4 \%)$ mulheres, 158 (83,1\%) apresentavam níveis pressórico pessoas, sendo $81(42,6 \%)$ homens e $109(57,4 \%)$ mulheres, 158 (83,1\%) apresentavam níveis pressóricos
controlados e $32(16,9 \%)$ não controlados. 32,8\% dos entrevistados não chegaram a completar o Ensino Fundamental, $62,1 \%$ eram casados, $9,5 \%$ estavam tratando a hipertensão arterial há menos de 1 ano. $61,1 \%$ Fundamental, $62,1 \%$ eram casados, $9,5 \%$ estavam tratando a hipertensão arterial há menos de 1 ano. $61,1 \%$
dos pacientes foram considerados aderentes ao tratamento. Observou-se diferença significativa entre os grupos para o domínio estado mental (Teste U de Mann-Whitney, $\mathrm{p}<0,05$ ), onde o grupo não controlado apresentou um pior estado mental do que o grupo controlado. Houve uma associação significativa entr adesão ao tratamento e controle da pressão arterial (Teste de $\chi 2, p<0,05$ ). Conclusão: Os pacientes que aderiram ao tratamento apresentaram melhor controle de seu nível pressórico, e isso se refletiu também na qualidade de vida.

\section{AVALIAÇÃO DA QUALIDADE DE VIDA POR SEXO EM PACIENTES IDOSOS COM FRATURA NA EXTREMIDADE PROXIMAL DO FÊMUR}

Autor: Amauri Milton Machado

Orientadora: Profa. Dra. Lourdes Conceição Martins

Defesa da Dissertação: 20/12/2010

Introdução: O envelhecimento traz consigo uma diminuição da capacidade funcional, um aumento das doenças crônicas, as quais quando não tratadas adequadamente podem deixar sequelas permanentes. $O$ doenças crônicas, as quais quando não tratadas adequadamente podem deixar sequelas permanentes. O
equilibrio e a marcha dependem de uma complexa interação entre as funções nervosas, osteomusculares, equilibrio e a marcha dependem de uma complexa interação entre as funções nervosas, osteomusculares, cardiovasculares e sensoriais, além da capacidade de se adaptar rapidamente às mudanças ambientais e
posturais, as quais com o avanço da idade sofrem alterações resultando em queda e consequente risco de fraturas. Objetivo: Avaliar a qualidade de vida de pacientes idosos que realizaram cirurgia de fratura
da extremidade proximal do fêmur estratificada por sexo. Métodos: Estudo transversal realizado da extremidade proximal do fêmur estratificada por sexo. Métodos: Estudo transversal realizado
com pacientes pós-cirurgia de fratura da extremidade proximal do fêmur realizada em dois hospitais com pacientes pós-cirurgia de fratura da extremidade proximal do fềur realizada em dois hospitais através do questionário de qualidade de vida SF36, e de um questionário de dados biodemográficos. Fo realizada a análise descritiva e teste U de Mann-Whitney. Resultados: Foram entrevistados 50 pacientes, com idade entre 60 e 97 anos, média de 74,5 (dp=10,8). Há uma prevalência de pacientes do sexo feminino, casados ou viúvos, cor branca e com baixo nível de instrução. A doença mais prevalente foi a hipertensão arterial sistêmica. Com relação à qualidade de vida houve uma diferença significativa entre os gêneros para os domínios capacidade funcional $(\mathrm{p}<0,05)$, dor $(\mathrm{p}<0,05)$, aspectos físicos $(\mathrm{p}<0,05)$, aspectos sociais $(\mathrm{p}<0,05)$ e saúde mental $(\mathrm{p}<0,05)$. Conclusão: Este estudo evidencia que os idosos pós-cirurgia de extremidade proximal de fêmur apresentaram uma qualidade de vida diferenciada com relação ao sexo.

\section{A SÍNDROME DE ESTAFA PROFISSIONAL EM RESIDENTES DA FMABC}

Autor: Erika Rita Colombo de Faria da Cunha

Orientadora: Profa. Dra. Lourdes Conceição Martins

Defesa da Dissertação: 20/01/2011

Objetivo: Avaliar o nível de Burnout e seu risco em residentes da Faculdade de Medicina do ABC. Casuística e Métodos: Estudo transversal através da utilização de dois questionários autoaplicativos com questões fechadas de múltipla escolha realizadas com residentes da Faculdade de Medicina do ABC no período de janeiro a março de 2010. Foi utilizado um questionário de dados sociobiodemográficos e de sentimentos com relação à residência, e o questionário que avalia síndrome de Burnout (Malasch e de sentimentos com relação à residencia, e o questionario que avalia sindrome de Burnout (Malasch proporções. Resultados: Responderam aos questionários 70 residentes. A idade média (desvio padrão) do grupo foi de $26,6(3,1)$ anos, variando entre 20 e 45 anos. Observa-se que há uma prevalência do sexo do grupo foi de $26,6(3,1)$ anos, variando entre 20 e 45 anos. Observa-se que há uma prevalência do sexo $(52,9 \%)$ apresentam risco de desenvolver Burnout médio, $15(21,4 \%)$ apresentam risco alto e $18(25,7 \%)$ risco baixo. Conclusão: A síndrome de Burnout é um sério problema entre os residentes da FMABC. 
PREVALÊNCIA DA SÍNDROME DE BURNOUT EM ANESTESISTAS DO MUNICÍPIO DE SANTO ANDRÉ

Autor: Fernando César Serralheiro

Orientadora: Profa. Dra. Lourdes Conceição Martin

Defesa da Dissertação: 20/01/2011

Introdução: A moderna estrutura social vigente na atualidade, que privilegia as leis de mercado com ao longo da história, hoje também se vê refletida no âmbito profissional na figura do indivíduo, sendo este avaliado a partir de parâmetros de produtividade e eficiència empresarial. Mostramos a relação desta exigências com o desenvolvimento da Síndrome de Burnout, estresse ligado diretamente a atividade de trabalho, caracterizada por baixa produtividade e absolutamente nenhuma sensação de prazer frente ao trabalho Objetivo: Verificar a prevalência da Síndrome de Burnout em anestesistas ligados à Faculdade

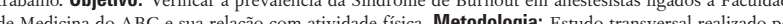
de Medicin do ABC e sua relação com atividade fisica. Metologia: Estudo transversal realizado por meio de Buratizado a análise descritiva e Tos dos ancis o domínio despersonalizaçá, onde quem não pratica atividade fisica apresenta um grau de despersonalização maio em relação àqueles que tom essa prática rotineiramente (teste $U$ de Mann-Whitney, $\mathrm{p}<0,05$ ). A maio Síndrome de Burnout. Conclusão: Embora a prevalência da síndrome neste grupo de anestesistas tenha se Síndrome de Burnout. Conclusão: Embora a prevalência da síndrome neste grupo de anestesistas tenha se
mostrado baixa, ela e suas repercussões apontam para a urgente necessidade de intervenções institucionais mostrado baixa, ela e suas repercussões apontam para a urgente necessidade de intervenções institucionais
com capacitação e apoio para que o profissional possa lidar com os aspectos objetivos e subjetivos d atividade assistencial específica de algumas profissões.

\section{ANÁLISE DA VARIABILIDADE DA SENSIBILIDADE BARORREFLEXA ENTRE RATOS DA MESMA LINHAGEM}

Autor: Caio Imaizur

Orientadores: Prof. Dr. Celso Ferreira e Prof. Dr. Luiz Carlos de Abreu Defesa da Dissertação: 21/02/2011

Objetivos: Comparar a sensibilidade barorreflexa em ratos conscientes da mesma linha. Método Ratos machos Wistar Kyoto (oito semanas de idade) foram estudados. Cânulas foram introduzidas n artéria aorta abdominal através da artéria femoral direita para medida da pressão arterial média (PAM) frequência cardíaca (FC). O ganho barorreflexo (GB) foi calculado como a razão entre a variação da $\mathrm{FC}$ em função da variação da PAM ( $\triangle \mathrm{FC} I \Delta \mathrm{PAM})$ testado com dose depressora de nitroprussiato de sódi (NPS, $501 \mathrm{lg} / \mathrm{kg}$, IV) e dose pressora de fenilefrina (FE, $81 \mathrm{lg} \mathrm{I} \mathrm{kg}$, IV). Dividimos os ratos em quatro grupos: 1) Barorreflexo bradicárdico reduzido (BR): $\mathrm{GB}$ entre -1 e $-2 \mathrm{bpm} / \mathrm{mmHg} ; 2$ ) Barorreflexo bradicárdico aumentado (BA): $\mathrm{GB}<-2 \mathrm{bpm} / \mathrm{mmHg}$ testado com $\mathrm{FE}$; 3) Barorreflexo taquicárdico Reduzido (TR): GB entre -1 e $-2 \mathrm{bpm} / \mathrm{mmHg}$; 4) Barorreflexo taquicárdico aumentado(TA): GB<-2 $\mathrm{bpm} / \mathrm{mmHg}$ testado com NPS. Foram consideradas significativas diferenças para $\mathrm{p}<0,05$. Resultados: Cerca de $82 \%$ dos ratos apresentaram redução do barorreflexo bradicárdico enquanto $22 \%$ apresentara

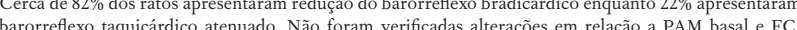
Paceração a PAM basal e FC, picos te FC. Consideraçóes finais: Houve na interpretação de estudos empregando WKY como um controle para o SHR.

\section{TRADUÇ̃̃O E VALIDAÇ̃̃O DO SELF TEST II - TESTE AUTOAPLICATIVO PARA RASTREAMENTO DE DEMÊNCIA}

Autora: Karol Casagrande Crepaldi

Orientadora: Profa. Dra. Ttânia C. de Toledo Ferraz Alves

Defesa da Dissertação: 22/03/2011

Introdução: O número de idosos que sofrem de doenças crônicas, incluindo déficits cognitivos, deverá aumentar nos próximos anos. Embora não exista cura definitiva para a demência, a melhor resposta ao tratamento é observada quando as intervenções farmacológicas e não farmacológicas são iniciadas nas tratamento é observada quando as intervençōes farmacologicas e não farmacologicas são iniciadas ná primeiras fases da doença. No entanto, a demência geralmente não é detectada nos serviços de saúde,

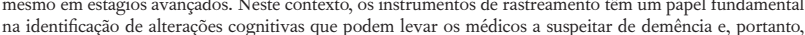
estabelecer, o mais rapidamente possível, o tratamento. Contudo, os testes disponíveis são de demorada aslicacãa e exigem supervisão especializada, o que limita sua utilização em ambientes clínicos com alta aplicação e exigem supervisão especializada, o que limita sua utilização em ambientes clínicos com alt demanda. O self Test 11 (STI) é um teste de rastreio para a demencia que é autoadministrado e que, portanto, pode ser aplicado com supervisão mínima. Objetivos: Os objetivos deste estudo foram: adaptar o ST 11 para o português brasileiro (STII-Br) e compará-Io com a versão original em inglês; e avaliar validade de construção da adaptação brasileira do STII, utilizando-a para avaliar indivíduos com diagnóstico de déficit cognitivo e, em seguida, comparando os resultados com os voluntários saudáveis. Métodos: Foram realizados quatro procedimentos (tradução, retrotradução, adaptação e pré-teste), a fim de realiza uma versão traduzida e adaptada para o português brasileiro do Self Test 11. Nós também selecionamos 157 validação. O declínio cognitivo foi avaliado por meio do Miniexame do Estado Mental (MEEM). Curva ROC e análises de correlação foram realizadas para o MEEM e o STII-Br. Resultados: Cento e cinco $(66,9 \%)$ participantes eram do sexo feminino. A idade média dos entrevistados foi de 73 anos (60-98), e a escolaridade média foi de 7 anos (4-21). Cinquenta sujeitos $(31,8 \%)$ apresentavam prejuízo cognitivo e $107(68,2 \%)$ não apresentavam declínio cognitivo. A área sob a curva ROC (AUROCC) foi de 0,84 (IC95\% 0,77-0,91). ponto de corte do STII- Br que apresentou o melhor balanço entre sensibilidade e especificidade foi de $24 / 25$ pos (cen $24 / 25$ pontos ( sensibilidade $=82 \%$, especificidade $=76 \%$ e correta classificação dos casos $=78 \%$ ). Conclusão: A versão brasileira do STII (STII-Br) mostrou-se um instrumento culturalmente apropriado e valido no rastreamento de declínio cognitivo em idosos com pelo menos quatro anos de escolaridade. O STII-B

\section{AVALIACÃO DA MECÂNICA PULMONAR E DOS PARÂMETROS HEMODINÂMICOS EM PACIENTES SOB REGIME DE ASPIRACÃO TRAQUEAL ABERTA E FECHADA EM VENTILAÇÃO MECÂNICA}

Autor: Rodrigo Daminello Raimundo

ca Akemi Sato

Defesa da Dissertação: 28/01/201

Introdução: A aspiração endotraqueal é um tratamento preventivo e também eficaz no combate à obstrução brônquica. Em pacientes submetidos à ventilacão mecânica, a aspiração de secreção intratraqueal pode ser realizada por dois tipos de sucção: sistemas abertos e fechados. O sistema de aspiração aberto (SAA), requer desconexão do paciente do ventilador para insercão do cateter, levando à perda da pressão expiratória final positiva (PFEP) e da fração de oxigênio. O sistema de aspiração fechado (SAF) não requer a desconexão do paciente do ventilador. Material e Métodos: Setenta e um pacientes foram randomizados. Após essa avaliação inicial, a pressão arterial sistólica (PAS), pressão arterial diastólica (PAD), pressão arterial média (PAM), frequência cardíaca $(\mathrm{FC})$, frequência respiratória ( $\mathrm{FR}$ ), saturação de pulso de oxigênio (Sp02), volume corrente (VC), pressão de pico (Ppico), pressão de platô (Pplatô), pressão expiratória final positiva (PEEP), o fluxo inspiratório (V), a complacência (C) e resistência das vias aéreas $(\mathrm{R})$ foram mensurados. Os procedimentos de aspiração foram cronometrados e duraram 10 segundos para colocar e retirar o cateter de aspiração e cada aspiração foi realizada
três vezes. Ao final do procedimento de aspiração, todos os dados foram coletados novamente. Resultados: Para três vezes. Ao final do procedimento de aspiração, todos os dados foram coletados novamente. Resultados: Para o SAA houve um aumento do momento inicial para o final nos parâmetros PAS, PAD, PAM e FC ( $\mathrm{p}=0,003$, $\mathrm{p}=0,001, \mathrm{p}=0,016, \mathrm{p}=0,012)$. A Ppico foi diferente no momento final em relação ao momento inicial $(\mathrm{p}=0,045)$. Houve aumento da resistência no momento inicial para o final ( $\mathrm{p}=0,017)$. No SAF, a PAM e FC aumentaram do momento inicial para o momento final $(\mathrm{p}=0,028, \mathrm{p}<0,001)$. Para o SAF a Ppico aumentou $(\mathrm{p}=0,017)$ e houve uma diminuição da resistência $(\mathrm{p}=0,007)$. Houve uma diferença significante na Ppico e $\mathrm{R}$ quando comparado SAA e o $\mathrm{SAF}(\mathrm{P}=0,017, \mathrm{p}=0,007)$. A constante de tempo e a pressão das vias aéreas aumentaram quando comparados o SAA com $\operatorname{SAF}(\mathrm{p}=0,019, \mathrm{p}=0,013)$. Conclusão: $\mathrm{O}$ aumento da resistência das vias aéreas no $\mathrm{SAA}$ em relação ao SAF sugere que esse é um fator a ser considerado na escolha do tipo de sistemas de aspiração traqueal. Além disso, as complicaçôes hemodinâmicas também podem ser um critério para a prescrição do SAF.

\section{VALIDACC̃̃O DOS MARCADORES DE DOENCCA RESIDUAL MÍNIMA (CK-19 E C-ERB-B2) EM CÂNCER DE MAMA POR RT- OPCR NA FRAÇÃO MONONUCLEAR DO SANGUE PERIFÉRICO}

Autora: Vivane Aparecida Vilas Bôas

Orientacr: Prof. Dr. Fernando Luiz Affonso Fonseca

Defesa da Dissertação: 18/03/2011

Objetivos: No câncer de mama, a detecção de células tumorais circulantes (CTCs) em sangue periférico está associada a um prognóstico ruim e a doença residual mínima (DRM). Vários métodos para detecção das CTCs em sangue periférico têm sido desenvolvidos para enriquecer as pesquisas nessa área. Um deles é o RT-qPCR, que pode detectar uma célula tumoral em milhões de células normais. O CK-19 e o c-erbB2 são dois dos marcadores epiteliais que refletem a presença das CTCs. Como o RT-qPCR fornece uma quantidade significante de informações sobre a expressão do gene, nós estamos propondo validar o uso do marcadores CK-19 e c-erb-B2 na detecção de CTCs em 23 doadoras e 22 pacientes ao diagnóstico usando o RT-qPCR para avaliar a sensibilidade e a especificidade, entre outros parâmetros, desses marcadores. Em nossa pesquisa, ambos os marcadores foram mais específicos do que sensíveis. Entretanto, o CK-1 foi ainda mais específico que o c-erb-B2 ( 91 e $83 \%$, respectivamente). Ele também foi mais sensível (23 e $14 \%$ respectivamente) e mais exato ( 95,2 e $93,6 \%$ respectivamente). Consequentemente, os valores preditivos positivo e negativo do CK-19 também foram melhores que do c-erb-82. Ambos os marcadores demonstraram ser extremamente lineares (correlação de 0,99 ). Precisão foi o único parâmetro em que o c-erb-B2 foi melhor que o CK-19. Tanto o CK-19 quanto o c-erb-B2 são marcadores válidos para o uso na DRM, mas não são os marcadores ideais devido a sua baixa sensibilidade. Entretanto, eles podem ser bon marcadores durante o tratamento quimioterápico e reduzir as chances de recaída.

\section{DOSAGEM DE ESTRADIOAL E ESTRONA EM PACIENTES COM CÂNCER DE MAMA METASTÁTICO APÓS USO DE LETROZOL A CADA 48 HORAS: UM ESTUDO PILOTO}

Autor: Jorge Henrique Santos Leal

Orientador: Prof. Dr. Auro Del Giglio

Defesa da Dissertação: 13/04/2011

Contexto e Objetivo: Pacientes com câncer de mama metastático sensíveis à hormônio se beneficiar do tratamento com inibidores da aromatase. O elevado custo e os efeitos colaterais podem limitar se uso. Letrozol, um potente inibidor da aromatase, tem meia vida em torno de 50 horas. Nosso objetivo foi avaliar os níveis de estradiol e estrona, qualidade de vida e efeitos adversos em pacientes com câncer de mama metastático após uso do letrozol a cada 48 horas, comparando com a posologia diária. Pacientes e Métodos: Nove pacientes com câncer de mama metastático, positivos para os receptores de estrógeno e/ou progesterona, foram incluídas neste estudo prospectivo, não controlado, em que todas foram submetidas a duas intervenções sequenciais: 30 dias em uso de letrozol $2,5 \mathrm{mg}$ via oral a cada 48 horas, seguido de 30 dias da mesma droga, na mesma dosagem, diariamente. Amostras sanguíneas para dosagem dos níveis de estradiol e estrona (quimioluminescência) foram coletadas antes do início do estudo (00), 030 e 060 . As toxicidades foram avaliadas de acordo com os critérios do NCI, 1999. Foi aplicado o questionário de qualidade de vida EORTC ala C-30. Resultados: Houve uma oscilação não esperada nas respostas hormonais, variando de zero até $75 \%$ dos níveis de estradiol e de zero a $72 \%$ dos níveis de estrona. Houve pacientes com escape hormonal. Não houve diferença estatística entre os tipos de intervenção Houve pacientes com escape hormonal. Não houve diferença estatística entre os tipos de intervenção
nos diferentes períodos analisados (00-030 vs $030-60)$. A análise de qualidade de vida mostrou melhora significativa apenas no item perda de apetite, mas com ganhos numéricos nos itens dor e sintomas no braço significativa apenas no item perda de apetite, mas com ganhos numericos nos itens dor e sintomas no braço com o uso da posologia experimental. As toxicidades foram mais brandas com a posologia a cada 48 horas, especialmente para o item fadiga. Conclusão: Em virtude da grande variação dos níveis hormonais, este
estudo não nos permite concluir que o uso de letrozol $2,5 \mathrm{mg}$ a cada 48 horas seja uma abordagem factivel. A melhora da qualidade de vida e redução dos efeitos colaterais sugere que futuros estudos abordem novas posologias desta droga com o intuito de melhorar sua tolerância e reduzir o custo. 


\section{INFLUÊNCIA DA MORFOLOGIA ESPERMÁTICA ESTRITA SOBRE OS RESULTADOS DE FERTILIZAÇÃO IN VITRO}

Autor: Milton Ghirelli Filh

Orientador: Prof. Dr. Sidney Glina

Defesa da Dissertação: 20/04/2011

Objetivo: Determinar a influência, sobre os resultados da FIV clássica, da concentração de espermatozoides ovais segundo o critério da morfologia espermática estrita, em homens com concentração espermática normal segundo os critérios da OMS. Pacientes e Método: A partir de revisão de prontuários, foram incluídos neste estudo casais inférteis apresentando causas femininas para infertilidade ou com infertilidade sem causa aparente, nos quais os homens apresentavam espermograma com valores normais para os parâmetros de concentração espermática, motilidade espermática e volume jac pres grupo A, pacions (1) taxa de gration

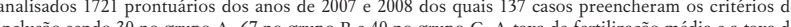
inclusão sendo 30 no grupo $\mathrm{A}, 67$ no grupo $\mathrm{B}$ e 40 no grupo $\mathrm{C}$. A taxa de fertilização média e a taxa de nascidos vivos for no rectivamente. 75,6 e 30,0\% no grupo $A, 82,3$ e 22,3\% no grupo B e 79,1 e $25,0 \%$ no grupo C. Não houve diferença estatistica entre os grupos em nenhuma das variáveis de desfech analisadas. Conclusáo: Os valores da morfologia espermática estrita segundo os critérios da OMS não tiveram influência sobre os resultados da fertilização in vittro clássica na amostra estudada.

\section{POLIMORFISMOS DE GENES RELACIONADOS AO METABOLISMO DO FOLATO (MTHFR, MTRR E MTR) EM HOMENS COM INFERTILIDADE IDIOPÁTICA}

Autor: Marcello Machado Gava

Orientador: Prof. Dr. Sidney Glin

Defesa da Dissertacio: $27 / 07 / 2011$

Introdução: O folato participa no metabolismo de aminoácidos, sínDissertação de nucleotídeos, metilação dos ácidos nucleicos, proteínas e lipídios. A deficiência de folato pode ser determinada genética ou dieteticamente prejudicando a função dessa via metabólica. Alguns autores sugeriram a associação de dieteticamente prejudicando a função dessa via metabolica. Alguns autores sugeriram a associação de distribuic̃ão ne plimorfismos dos anes MTHFR, MTRR MTR em homens com infertilidade idiopática homens férteis como controles. Métodos: Estudo caso-controle, que incluiu 133 homens com infertilidade

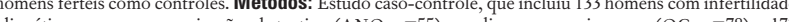
idiopática com azoospermia não obstrutiva ( $\mathrm{ANO}, \mathrm{n}=55$ ) ou oligozoospermia grave $(\mathrm{OG}, \mathrm{n}=78)$ e 173 homens férteis como contes Os polima (ANO n e MTR A2756G foram estudados por qPCR. Os resultados foram analisados estatisticamente e o valo de $\mathrm{p}<0,05$ foi considerado significativo. Resultados: $\mathrm{A}$ análise individual dos polimorfismos revelo associação entre o polimorfismo MTHFR C677T em ambos os grupos ANO ( $\mathrm{p}=0,018)$ e OG $(\mathrm{p}<0,001)$. Considerando os polimorfismos MTHFR A1298C, MTHFR G1793A e MTRR A66G, nenhuma diferenç̧ foi encontrada entre os grupos ANO ou OG. Em relação ao polimorfismo MTR A2756G foi encontrada, diferença significativa, entre o grupo ANO e controles, $p=0,017$. No entanto, não foi encontrada diferenç estatística entre os grupos OG e controles. Os genótipos combinados dos polimorfismos do gene MTHFR não identificou um haplótipo associado com a infertilidade idiopática. A análise combinatória dos três polimorfismos $M T H F R, M T R R$ e $M T R$ não apresentou diferença entre casos e controles. Conclusão: $\mathrm{O}$ resultados sugerem que os polimorfismos MTHFR C677T e MTR A2756G podem ser importantes fatores genéticos de predisposição para a infertilidade idiopática masculina.

\section{AVALIAÇÃO DA MUCOSA ORAL DE PACIENTES COM DOENÇA DE CROHN: ESTUDO CASO-CONTROLE}

\section{Autor: Renata Bęerra Coutinho Cruz}

Orientador: Prof. Dr. Wilson Roberto Catapan

Defesa da Diss

Introdução: A doença de Crohn apresenta um curso protrardo, cujo diagnóstico pode ser difícil. A presença de lesões em mucosa oral pode aumentar a suspeita diagnóstica. Objetivo: Avaliar a mucosa oral de pacientes com doença de Crohn em comparação com o grupo controle. Métodos: Estudamos 124 pacientes adultos, com idade superior a 18 anos de ambos os sexos. Sessenta e dois pacientes com doença de Crohn e sessenta e dois pacientes do grupo controle, pareados quanto ao sexo e idade. As lesões em mucosa oral pesquisadas foram úlceras aftosas, granulomatose orofacial, pregas mucosas, leucoplasia e pioestomatite vegetante. Ambos foram úlceras aftosas, granulomatose orofacial, pregas mucosas, leucoplasia e pioestomatite vegetante. Ambo os investigadores, a dentista e o médico eram cegos quanto ao diagnóstico e aos achados odontológico respectivamente. Resultados: Ao todo apenas seis pacientes apresentavam lesões em mucosa oral. Cinco destes pacientes eram do grupo controle (dois com hiperplasia fibrosa devido a trauma secundário a pródissertação, um com herpes labial simples, um com hemangioma e um com líquen plano). Apenas um pacient apresentava herpes simples. Alguns pacientes relataram história prévia sugestiva de afta. Seis pacientes eran do grupo controle $(9,6 \%)$ e nove eram do grupo com doença de Crohn (14,5\%). Não foram encontrada granulomatose orofacial, pregas mucosas, leucoplasia e pioestomatite vegetante. Conclusão: Lesões orais não foram indicadores úteis da presença de doença de Crohn na população analisada.

\section{REVACINAÇÃO CONTRA HEPATITE B NOS PACIENTES EM} HEMODIÁLISE: QUANDO?

Autor: Munir Akar Ayub

Orientadora: Profa. Dra. Ethel Zimberg Chehte

Defesa da Dissertação: 10/06/2011

Objetivos: A hepatite B é uma doença amplamente disseminada e é responsável pelo aparecimento de metad hemodiálise são considerados como grupo de alto risco. Nesses pacientes a vacina contra a hepatite B não apresenta boa eficácia, ao contrário do que acontece nos indivíduos imunocompetentes. A literatura médica indica a vacinação antes do início da hemodiálise com 4 doses duplas $(40 \mathrm{mg})$. Mesmo assim quase $1 / 3$ não responde com a produção suficiente de anticorpos. Anualmente uma nova sorologia deve ser realizad nos indivíduos que responderam adequadamente e naqueles que estiverem com níveis de anticorpos inferiores a $10 \mathrm{UI} / \mathrm{mL}$ uma nova dose de reforço deve ser oferecida. Neste estudo foram acompanhados 83 pacios 83 pacientes em hemodialise após a vacinação e a cada 2 meses foram colhidos sorologias quantitativas durante 1 ano. Observamos que 34/83 (41\%) não responderam a vacinação, $18 / 83(21,7 \%)$ responderam $100 \mathrm{Ul} / \mathrm{mL}$ (bons respondedores). Diabetes e hipertensão arterial isoladamente ou concomitantemente apresentaram pior resposta a vacinação. Todos os pacientes apresentaram níveis decrescentes de anticorpos durante o período observado. No grupo dos pacientes mal respondedores $(44,4 \%)$ apresentavam níveis de durante o periodo observado. No grupo dos pacientes mal respondedores $(44,4 \%)$ apresentavam niveis de
anticorpos inferiores a $10 \mathrm{UI} / \mathrm{mL}$ no $6^{\circ}$ mês de acompanhamento. $\mathrm{O}$ estudo sugere que nos pacientes mal respondedores seja feito um acompanhamento sorológico pelo menos a cada semestre para assim indicar ou respondedores seja feito um acompanhamento sorológico pelo menos a cada semestre
não a revacinação e dessa forma evitar que fiquem suscetiveis durante esse período.

\section{ESTUDO DO POLIMORFISMO C1858T DO GENE PTPN22 EM MULHERES PORTADORAS DE ENDOMETRIOSE}

Autor: Fabiane Monteiro de Carvalho Souza Gomes

Orientador: Prof. Dr. Caio Parente Barbos

Defesa da Dissertação: 16/08/201

Introdução: A endometriose tem sido considerada uma doença autoimune e, recentemente, polimorfismo C1858T do gene PTPN22 foi relacionado ao desenvolvimento de autoimunidade. O objetivo do estudo oi determinar a frequência do polimorfismo C1858T do gene PTPN22 em mulheres brasileiras con ndometriose e em população controle. Métodos: Estudo caso-controle que incluiu 140 mulheres com endometriose e um grupo controle constituído por 180 mulheres saudáveis e férteis, sem história de endometriose e/ou doenças autoimunes da Faculdade de Medicina do ASC. O polimorfismo C1858T do gene PTPN22 foi estudado por RFLP-PCR (Restriction Fragment Lenght Polymorphism). Resultados: O genótipos CC, CT e TI do polimorfismo C1858T do gene $P T P N 22$ apresentaram frequência de $67,9,30,0 \mathrm{e}$ $2,1 \%$ nas mulheres com endometriose $(\mathrm{p}=0,008)$ e $82,8,16,1$ e 1,1\% no grupo controle. Quando separamos os grupos de acordo com o estadiamento, observamos que genótipos CC, CT e TI estavam frequentes en $76,2,19,0$ e $4,8 \%$ nas mulheres com endometriose mínima/leve $(\mathrm{p}=0,173)$ e $61,0,39,0 \mathrm{e} 0,0 \%$ nas mulhere 年 com endometriose moderada/grave $(\mathrm{p}<0,001)$. Alelo $\mathrm{C}$ e T estava presente em 82,9 e $17,1 \%$ nas mulhere com endometriose $(\mathrm{p}=0,004), 85,7$ e 14,3\% nas mulheres com endometriose mínima/leve $(\mathrm{p}=0,148) ; 80$, e $19,5 \%$ e nas mulheres com endometriose moderada/grave $(\mathrm{p}=0,002)$ e 90,8 e $9,2 \%$ no grupo controle.
Conclusão: Os dados sugerem que em mulheres brasileiras o polimorfismo PTPN22 C1858T pode ser um fator genético importante predisponente para a endometriose, especialmente, na doença avançada.

\section{O PAPEL DO DNA PLASMÁTICO NO DIAGNÓSTICO DE CÂNCER DE PRÓSTATA}

Autor: Marcelo Langer Wroclawski Orientadores: Prof. Dr. Antonio Carlos Lima Pompeo e Prof. Dr. Auro Del Giglio Defesa da Dissertação: 19/09/2009

Introdução: $\mathrm{O}$ câncer de próstata $(\mathrm{CP})$ é a segunda neoplasia mais comum em homens. Seu diagnóstico em grande parte das vezes é motivado por alterações nos níveis de antígeno prostático específico (PSA), exame com baixa especificidade. Objetivo: Avaliar o papel diagnóstico e prognóstico do DNA plasmático em pacientes com suspeita de ou já com diagnóstico histológico de adenocarcinoma de próstata. Métodos: Foram inclú́dos 133 homens

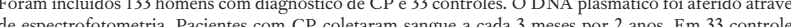
de espectrofotometria. Pacientes com CP coletaram sangue a cada 3 meses por 2 anos. Em 33 controles Com a com a biopsia prostática. Resultados: Admitindo-se um valor de corte do DNA plasmático de $140 \mathrm{ng} / \mathrm{mL}$, a área sob

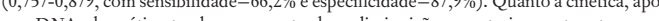
a biopsia prostática o DNA plasmático tende a apresentar leve diminuição o posteriormente retoma ao seus níveis basais em aproximadamente 1 semana. Não houve relação estatisticamente significante entre o hivers de DNA Plas bioquímica (SLRB). Entretanto, após seguimento médio de 13,5 meses, observamos uma SLRB mais curta nos pacientes com ao menos uma dosagem de DNA plasmático acima de $140 \mathrm{ng} / \mathrm{mL}$ durante o seguimento $(\mathrm{p}=0,048)$. Conclusões: DNA plasmático é um potencial biomarcador para o diagnóstico do $\mathrm{CP}$ uma ferramenta que poderá ser utilizada no seguimento destes pacientes. 
RELAÇÃO ENTRE AS DOSAGENS HORMONAIS EM PACIENTES COM INFERTILIDADE SECUNDÁRIA E POLUIÇÃO DO AR

Autor: Odair Ramos da Silva

Orientador: Prof. Dr. Fernando Luiz Affonso Fonseca

Defesa da Dissertação: 30/09/2011

Introdução: Estudos atuais têm associado a exposição a poluentes com ação disruptora sobre o sistema endócrino a problemas de infertilidade tais como, redução da fertilidade masculina, anormalidades no desenvolvimento sexual, entre outros. Objetivos: Diante de tantas evidências que indicam que a saúde do homem pode sofrer consequências adversas da exposição a poluentes presentes que interagem com o sistema endócrino, neste trabalho buscou-se correlacionar os efeitos dos poluentes nos exames hormonais sexuais masculinos e femininos em sujeitos que procuraram o serviço de reprodução assistida do ambulatório de especialidades da Faculdade de Medicina do ABC. Métodos: Este estudo quantitativo, retrospectivo, de especialidades da Faculdade de descrivo, com cort Facho estimulante (FSH), hormônio luteinizante (LH), estrógeno, progesterona, testosterona e prolactina foran realizados e relacionados com dados dos poluentes: monóxido de carbono $(\mathrm{CO})$, ozônio $\left(0_{3}\right)$, dióxido de enxofre $\left(\mathrm{SO}_{2}\right)$, dióxido de nitrogênio $\left(\mathrm{NO}_{2}\right)$ e material particulado $<10 \mu \mathrm{m}$ em diầmetro aerodinâmico (PM10). Resultados: Para o hormonio prolactina encontrou-se um nivel de significância de $5 \%(p<0,05$, $\mathrm{p}<0,005$ e $\mathrm{p}<0,005)$ como fator de risco ou seja, há o risco de esse hormônio estar alterado em relação a poluente em até 21,17 vezes. Conclusão: Nossos resultados sugerem que o PM10 foi o responsável pela alterações observadas no hormônio prolactina, reforçando o conceito de que poluição atmosférica pode ter uma ação disruptora na saúde reprodutiva humana.

\section{ENSAIO PROSPECTIVO DUPLO-CEGO RANDOMIZADO DA ADIÇÃO DE GABAPENTINA A ONDONSETRON E DEXAMETASONA NO CONTROLE DA EMESE INDUZIDA POR QUIMIOTERÁPICOS ALTAMENTE E MODERAMENTE EMETOGÊNICOS}

Autor: Felipe José Silva Melo Cruz Orientador: Prof. Dr. Auro Del Giglio

Defesa da Dissertação: $19 / 10 / 2011$

Introdução: Náusea e vômitos induzidos por quimioterapia (NVIQ) são efeitos colaterais desagradáveis que afetam muitos pacientes submetidos a quimioterapia emetogênica, apesar do uso das medicações antieméticas. Este estudo tem por objetivo avaliar a eficácia e a segurança da gabapentina na prevenção de NVIQ após o primeiro ciclo de quimioterapia moderada e altamente emetogênica. Método: Oitenta pacientes selecionados a receber pela primeira vez quimioterapia moderada ou altamente emetogênica foram recrutados a participar deste estudo randomizado, duplo-cego, placebo controlado. Todos os pacientes receberam no dia um: ondansetron $8 \mathrm{mg}$, dexametasona $10 \mathrm{mg}$ : e ranitidina $50 \mathrm{mg}$ antes da quimioterapia; receberam no dia um: ondansetron $8 \mathrm{mg}$, dexametasona $10 \mathrm{mg}$ : e ranitidina $50 \mathrm{mg}$ antes da quimioterapia; gabapentina $300 \mathrm{mg}$ ou placebo: cinco e quatro dias antes da quimioterapia $1 \mathrm{x} /$ dia, três e dois dias antes da gabapentina $300 \mathrm{mg}$ ou placebo: cinco e quatro dias antes da quimioterapia $1 \mathrm{x} /$ dia, trés e dois dias antes da quimioterapia $2 \mathrm{x} /$ dia, um dia antes a cinco dias depois da quimioterapia $3 \mathrm{x} /$ dia. Os objetivos primarios do estudo foram proteção completa de náusea e vômitos durante todo o período do estudo (dia I ao dia 5) além de proteção completa durante a fase tardia $(24 \mathrm{~h}$ a $120 \mathrm{~h}$ após a quimioterapia). Resultados: A proporção de pacientes que atingiram resposta completa melhorou de 40 a $62,5 \%(\mathrm{p}=0.04)$ quando comparado o grupo
controle e o grupo da gabapentina, respectivamente. No subgrupo de pacientes que atingiram controle controle e o grupo da gabapentina, respectivamente. No subgrupo de pacientes que atingiram controle
completo na fase aguda, a percentagem de pacientes que atingiram controle completo tardio foi maio no grupo da gabapentina $(89,3 \times 60,7 \%, \mathrm{p}=0.01)$. Não houve diferença entre os grupos com relação ao efeitos adversos analisados. Conclusão: A gabapentina melhorou significativamente o controle complet de NVIQ e parece ser mais efetiva no controle da NVIQ tardia.

\section{ESTUDO DOS POLIMORFISMOS DO GENE FOXP3 EM MULHERES BRASILEIRAS COM E SEM ENDOMETRIOSE}

Autor: Gustavo Mendonça André Orientadora: Profa. Dra. Bianca Bianco

Defesa da Dissertação: 08/11/2011

Introdução: Alteraç̃os no mecanismo imunológico foram sugeridas na patogênese da endometriose e estudos recentes associaram o gene FOXP3 (forkhead box P3) com a homeostasia do sistema imune. Nosso objetivo foi avaliar polimorfismos do gene FOXP3 (rs3761549, rs3761548, rs2232368, rs2232366 e rs2280883) em um grupo de mulheres inférteis com e sem endometriose e controles. Métodos: Fo realizado um estudo caso-controle composto por 177 mulheres inférteis com endometriose, 71 mulheres com infertilidade idióática e 171 mulheres em idade fértil como controles. Os polimorfismos do gene FOXP3 form identificados pelo sistema (PCR). Os rs (PCR). Os resultados foram analisados estatistica por polin. e rs2232368 polimoris associado à infertilidade idiopática. Conclusão: Este é o primeiro estudo a relatar uma associação entre polimorfismos do gene $F O X P 3 \mathrm{e}$ a endometriose elou infertilidade. Esses achados requerem replicação em outras populações, mas sugerem que os polimorfismos do gene FOXP3 podem ser associados com o risco de infertilidade idiopática (rs2280883 e rs2232368) e endometriose (rs3761549) em mulheres brasileiras.
ASSOCIACÕES ENTRE IMPULSIVIDADE, COMPULSÃO ALIMENTAR E OBESIDADE EM ADOLESCENTES USUÁRIOS DO AMBULATÓRIO DE HEBIATRIA DA FACULDADE DE MEDICINA DO ABC

\section{Autor: Cibele Pereir}

Thehter

Defesa da Dissertação: 07/10/2011

A população obesa, a despeito dos elementos físicos, não é homogênea sob os aspectos psicológicos. Dentre les, a impulsividade, um tra le tempermento, nâ êl lugar de importância no âmbito da compulsão limentar, um agente tanto etiológico como mantenedor da obesidade. A impulsividade é avaliada por instrumentos de autorrelato na maioria dos estudos e neste propomos a avaliação pelo Teste Palográfico. Métodos: Neste estudo, 60 adolescentes (10-20 anos; Md: 13,97 anos; DP 2,17), 34 do sexo feminino 26 do sexo masculino, usuários do ambulatório de hebiatria da Faculdade de Medicina do ABC foram avaliados quanto ao índice de massa corporal, compulsão alimentar pela Escala de compulsão alimenta impulsividade pelo Teste palográfico e Escala de impulsividade de Barratt. Resultados: A compulsão alimentar foi mais prevalente no grupo feminino e a impulsividade no grupo masculino. $38 \%$ do participantes estavam acima do peso saudável e destes, 13\% simultaneamente com obesidade/obesidad grave, compulsão alimentar e altos escores para impulsividade. A associação entre IMC e impulsividade pontuou valores próximos do nível de significância $(\chi 2=14.85, \mathrm{DF}=8, \mathrm{p}=062)$. Conclusão: Os resultados satisfazem condições para a replicação do protocolo em amostras maiores e estratificadas por sexo.
CARCINOMA DUCTAL IN SITU MAMÁRIO EM BIÓPSIA POR AGULHA GROSSA E SUA CORRELAÇ̃̃O COM COMPONENTE INTRADUCTAL EXTENSO NO ESPÉCIME CIRÚRGICO

Autor: Guerino Barbalaco Neio

Orientador: Prof. Dr. Luiz Carlos de Abreu

Defesa da Dissertação: 04/11/2011

Introdução: Carcinoma ductal in situ extenso (CIE) em lesões invasivas corresponde ao percentual de

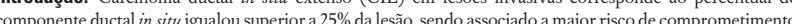
de margens em cirurgias conservadoras. Objetivo: Identificar a presença e porcentagem de carcinoma ductal in situ (GOlS) em biópsias por agulha grossa (BAG) nas lesões ductais invasivas e ou microinvasivas como um preditor de componente ductal in situ extenso em espécimes cirúrgicos. Método: Trata-se de estudo retrospectivo onde foram selecionadas amostras de BAG contendo somente carcinomas ductais invasivo ou microinvasivos e seus respectivos espécimes cirúrgicos, durante o período de 2004 a 2006 provenientes de pacientes assistidas no Serviço de Mastologia da Faculdade de Medicina do ABC. Foram selecionado 90 casos, de acordo com os critérios estabelecidos, sendo quantificado em cada uma das amostras obtidas por BAG o percentual de COIS presente e o padrão histológico do componente in situ, os quais foran comparados aos achados provenientes dos espécimes cirúrgicos respectivos. Todas as amostras de BAG foram avaliadas pelo mesmo patologista, não se atendo ao grau histológico, do COIS no componente invasivo, mas

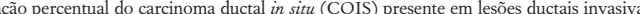
na BAG, localizadas intra e peritumoral, sendo distribuída em percentual e divididas em categorias, de acordo com a quantidade de COIS. Estes foram descritos como: $(1=0 ; 2=1$ a $5 \% ; 3=6$ a $24 \% ; 4=25$ a $50 \% ; 5=51$ $75 \%$ e $6=76$ a $99 \%)$. Resultados: A distribuicão do percentual de GOlS na BAG por categoria seguiu-se em: $1=63,3 \% ; 2=12,2 \% \cdot 3=12,2 \% ; 4=5,6 \% 5=1,1 \%$ e $6=5,6 \%$ A analise por reoress̃o lóística demontrou que percentuais de COIS em lesooes ductais invasivas e ou microinvasivas em BAG acima de $45 \%$ refletem presença de GIE na peça cirurgica em $100 \%(\mathrm{p}<0,001)$ dos casos, com especificidade de $100 \%$, acurácia de
$83,3 \%$ e índice de falso-positivo de $0 \%(\mathrm{p}<0,001)$. Conclusão: Há relação direta entre o percentual de COIS presente em GOl obtido por BAG e o achado de CIE na peça operatória.

\section{VITILIGO EM DIFERENTES GRUPOS ETÁRIOS: ANÁLISE DO PERFIL CLÍNICO-EPIDEMIOLÓGICO}

Autor: Juliano Cesar de Barros

Orientador: Prof. Dr. Carlos D’Apparecida Santos Machado Filho

Defesa da Dissertação: $09 / 11 / 2011$

Introdução: $O$ vitiligo é uma desordem cutânea caracterizada por máculas acrômicas (brancas) em qualquer parte da pele e/ou mucosas, que atinge de 0,5 a $2 \%$ da população mundial. Existem poucas publicações mundiais sobre vis quasil, com exceção de estudo sobre vitiligo. Objetivos: Verificar o perfil clínicoe avaliar o comportamento da doença em diferentes com vitiligo, no período de janeiro de 2001 a maio de 2006, atendidos na Faculdade de Medicina do ABC, localizada na região metropolitana do Estado de São Paulo, Brasil. Resultados: Observou-se predomínio do sexo feminino com 416 casos $(62,2 \%)$, e do grupo etário adulto com 406 casos $(62,5 \%)$. Ocorreram maiores picos de incidência entre a segunda e terceira décadas de vida (18,3 e 16,9\% respectivamente), o fotótipo 3 foi o mais frequente $(49,9 \%)$. Houve maior prevalência do vitiligo segmentar entre crianças e adolescentes (36,4\%), comparando-se com adultos (11,3\%) e idosos (6,7\%), e o vitiligo de comportament estável também foi proporcionalmente mais frequente na infância e adolescência (46,2\%), do que no adultos $(32,5 \%)$ e idosos $(36,7 \%)$. Conclusões: Os achados deste estudo ambulatorial são semelhantes aos encontrados em estudos realizados em outros páses, destacando-se a maior prevalência do vitiligo segmentar e do vitiligo com evolução estável entre crianças e adolescentes. 


\section{AVALIAÇÃO DOS FATORES DE RISCO PARA DOENÇAS} ENDOMETRIAIS EM MULHERES MENOPAUSADAS

Autor: Marcelo Ettruri Santos

Orientadora: Profa. Dra. Angela Mara B. de Souza van Mimwegen

Defesa da Dissertação: 22/11/2011

Introdução: As doenças do endométrio na pós-menopausa incluem pólipos, hiperplasia e adenocarcinoma. A patogênese dessas doenças ainda não é bem compreendida até o momento. O desequilíbrio entre A patogênese dessas doenças ainda não é bem compreendida até o momento. O desequilibrio entre proliferação e apoptose no endométrio e um elemento importante no processo, e os fatores que podem estar sistêmicas crônicas. Estudos epidemiológicos sugerem que obesidade, diabete mellitus, hipertensão arterial e estrogenioterapia isolada são fatores de risco para o desenvolvimento do câncer de endométrio. Em e estrogenioterapia isolada são fatores de risco para o desenvolvimento do câncer de endométrio. Em
algumas circunstâncias, o carcinoma desenvolve-se a partir de uma hiperplasia ou pólipo endometrial. Este fato leva alguns autores a sugerirem que os fatores de risco para desenvolvimento de hiperplasia pólipo seriam os mesmos do carcinoma endometrial. Entretanto, não há consenso na literatura de que as três doenças endometriais apresentem os mesmos fatores de risco para seu desenvolvimento. Objetivo: dentificar os fatores de risco para doenças endometriais (pólipos, hiperplasia e câncer) em mulheres na pósmenopausa com sangramento vaginal e/ou com exame ultrassonográfico alterado. Resultados: Foran avaliadas retrospectivamente 1.102 histeroscopias. A média de idade das pacientes foi de $61,9: \mathrm{t} 9,1$ anos e tempo médio de menopausa foi de 12,9 :t 9,2 anos. O espessamento do endométrio foi a principal indicação de histeroscopia ( 954 casos $/ 86,6 \%$ ). Pólipo endometrial foi o achado mais frequente ( 628 pacientes $57 \%$ ). Hiperplasia e adenocarcinoma foram diagnosticadas em 32 casos. Observou-se associação significativa con idade, incidência de abortamento, tempo de menopausa, HAS, IMC aumentado e terapia de reposição hormonal com o pólipo endometrial. A análise do risco relativo por cada tipo de doença mostrou o tempo de menopausa (OR1,56; IC95\% 1,18-2,07), HAS (OR1,38; IC95\% 1,05-1,73) e IMC aumentado (OR1,45; (O) de risco para o desenvolvimento de hiperplasia e câncer de endométrio. Conclusão: Os resultados deste estudo sugerem que as doenças endometriais não apresentam os mesmos fatores de risco.

\section{EFEITOS DA BLEFAROPLASTIA NA SÍNDROME DA DISFUNÇÃO LACRIMAL}

Autora: Juliana Silverio

Dr. José Ricardo Carvalho Lima Rehder Defesa da Dissertação: 01/12/201

Objetivo: Avaliar a relação da blefaroplastia superior com a Síndrome da Disfunção Lacrimal. Métodos: Estudo prospectivo. Pacientes com indicação cirúrgica para correção de dermatocálase em pálpebra superio de ambos os olhos foram avaliados através de história clínica e exame oftalmológico geral completo, incluindo exames como teste de Schirmer I, tempo de ruptura do filme lacrimal, coloração com Lissamin Verde e Fluoresceína, teste da sensibilidade corneana com estesiômetro de Cochet-Bonnet e teste subjetivo pelo questionário Ocular Surface Disease Index. Os exames foram realizados antes e após 90 dias da cirurgia. Resultados: Trinta pacientes foram incluídos neste estudo, porém apenas 23 pacientes completaram seguimento. Dezenove eram do sexo feminino e a idade dos pacientes variou de 63 a 87 anos (média 69,56). $\mathrm{O}$ teste de Schirmer I demonstrou uma melhora estatisticamente significativa da produção lacrimal no pós-operatório $(\mathrm{p}=0,021)$. Os resultados do tempo de ruptura lacrimal, colorações com Lissamina verde Fluoresceína foram considerados estatisticamente não significantes. Com relação à análise dos resultado obtidos com o estesiômetro de Cochet-Bonnet, 7 pacientes apresentaram uma melhora na sensibilidade

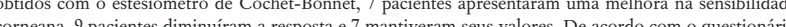
作 Ocular Suface Disease mas a análise estatistica mostrou um resultado não significante $(\mathrm{p}=0,702)$. Conclusão: Neste trabalho obs
IDENTIFICAÇÃO DOS FATORES RELACIONADOS À RECIDIVA EM PACIENTES COM NEOPLASIA INTRAEPITELIAL CERVICAL (NIC) DE ALTO GRAU SUBMETIDO À CIRURGIA DE ALTA FREQUÊNCIA (CAF)

Autora: Patricia Luchesi Bastidas

Patuardo Fernandes

Defesa da Dissertação: 22/11/2011

Objetivo: Identificar fatores associados com a recorrência da doença em pacientes com Neoplasia Intraepitelial Cervical (NIC) de alto grau que foram submetidas à Cirurgia de Alta Frequência (CAF). Método: Estudo de caso-controle que incluiu 103 pacientes. As pacientes que foran incluídas submeteram-se a conização CAF por diagnóstico histopatológico de NIC 11 e 11 I. Foran realizados exames de seguimento a cada seis meses com a coleta de colpocitologia oncológica e exame colposcópico com biópsias quando necessário, pelo período mínimo de 12 meses. Cura foi definida quando os exames permaneceram normais por 24 meses e recidiva quando a citologia e/ou a biópsia demostraram recidiva da lesão após 12 meses, ocasião em que as pacientes se submeteram à nov CAF. Para determinar o odds ratio da recorrência da lesão usamos o modelo de regressão logística binária por meio do programa SPSS 17.0. Resultados: Houve porcentagens maiores de recorrência da lesão em pacientes na pós-menopausa $(\mathrm{p}=0,007$, odds ratio $\mathrm{rOR}]=7,72,95 \%$ de intervalo de confiança $[\mathrm{IC}]=1,73-34,45)$, naquelas com margens cirúrgicas endocervicais comprometidas $(\mathrm{p}=0,004$ odds ratio $\mathrm{rOR}]=8,912,95 \%$ de intervalo de confiança $[\mathrm{IC}]=2,025-39,221$ ), e finalmente, nas con volume de peça cirúrgica menor que $14,06 \mathrm{cc}(\mathrm{p}=0,004$, odds ratio $\mathrm{rOR}]=14,47,95 \%$ de intervalo de confiança [IC] 2 ,321-90,210) 0 modelo demonstrou que estas varí́veis representam fatores de risco ndependentes Conclusão: Foram relacionados com recorrência da doença em pacientes com les̃ó le de alto grau (NIC 11 ou 11I) que se submeteram à CAF: mulheres na pós-menopausa, a presença d
margens endocervicais comprometidas e o volume da peça cirúrgica menor que $14,06 \mathrm{cc}$.

\section{ANALISE TOXICOLÓGICA E DE EFICÁCIA DA APLICAÇÃO TÓPICA DE FORMULAÇÃO EM GEL FLUÍDO COM IGF LIPOSSOMADO PARA O CRESCIMENTO CAPILAR}

Autor: Rafael de Castro Ferreira

ndo Luiz Affonso Fonseca

Defesa da Dissertação: 05/12/2011

Insulin-like growth factor-I (IGF-I) mostrou-se como uma interessante opção no tratamento de alopecia areata exercendo um sistema de sinalização no ciclo de crescimento capilar, bem como ação reguladora no controle fisiológico do crescimento capilar, prevenindo que os folículos adentrem em fase catágena. Essas funções fazem dele uma alternativa válida como tratamento adicional de alopecia. Mas como outra células podem ser influenciadas durante o tratamento, se faz necessário assegurar que a aplicação tópica de IGF-1 lipossomado veiculado em uma formulação de gel fluido não induz nenhum risco toxicológico. A mielotoxicidade e a hepatotoxicidade foram avaliadas utilizando como modelo animal o Mesocricetu auratus tratado com formulação placebo com base de gel fluido no grupo controle, enriquecida com $1 \%$ de IGF-1 no grupo $1 \%$ e enriquecida com $3 \%$ no grupo $3 \%$. AST e AL T não demonstraram alteraçõe significativas entre os grupos tratados e o grupo controle. Observou-se alterações hematopoiéticas significativas, todavia elas não são suficientes para caracterizar mielotoxicidade. O teste de ELISA não demonstrou aumento dos níveis plasmáticos de IGF-1. A eficácia foi determinada macroscopicamente pel analise dermatoscópica da densidade do pelo e microscopicamente pela avaliação do diâmetro do pelo Ambas as análises demonstraram que o grupo 3\% apresentou crescimento do pelo acelerado em relação aos demais grupos . é seguro e apresenta maior eficácia no grupo tratado com $3 \%$.

\section{CARACTERIZAÇÃO DO SISTEMA SENSÓRIO MOTOR ORAL DE PACIENTES COM LIPOATROFIA FACIAL QUE VIVEM COM AIDS}

Autora: Karina Viviani de Oliveira Pessốa

Orientador: Prof. Dr.

Defesa da Dissertação: 06/12/2011

Introdução: A Síndrome da Lipodistrofia em pessoas que vivem com AIDS caracteriza-se pel redistribuiçáo da gordura corporal e anormalidades metabólicas e está associada ao uso da terapia antirretroviral. É considerada socialmente impactante por reduzir a qualidade de vida e sua prevalência pode variar de 6 a $69 \%$. A Lipoatrofia Facial é considerada a que acarreta maior impacto psicológico. Objetivo: Caracterizar o Sistema Sensório Motor Oral de pacientes com Lipoatrofia Facial que vivem com AIDS. Método: Estudo transversal com 64 pacientes que vivem com AIDS, atendidos no Ambulatório de Lipodistrofia, que foram avaliados para caracterização das estruturas do Sistema Sensório Motor Oral por meio do Procto Oral dos pacientes deste estudo indicou alterações de tônus e de mobilidade associadas à perda da gordur subcutânea, causada pela lipoatrofia facial. Conclusaáo: As alterações apresentadas na morfologia e na
função do Sistema Sensório Motor Oral estão associadas à Lipoatrofia Facial em pacientes que vivem com AIDS, agravando a aparência da face.

\section{IMPACTO DA CIRURGIA BARIÁTRICA NA INGESTÃO DE NUTRIENTES}

Autora: Rosana Gomes de Torres Rossi

Orientadora: Profa. Dra. Roseli Oselka Saccardo Sarni

Defesa da Dissertação: 07/12/2011

Introdução: Deficiências nutricionais, especialmente de micronutrientes, podem ocorrer em indivíduos obesos. O tratamento cirúrgico pode agravar ou desencadear essas deficiências na dependência do tipo de obesos. O tratamento cirúrgico pode agravar ou desencadear essas deficiências na dependência do tipo de procedimento, consumo alimentar e suplementação. O objetivo do presente estudo foi avaliar a ingestão
de nutrientes de mulheres submetidas à cirurgia bariátrica. Métodos: Por meio de estudo transversal controlado, 44 mulheres adultas, submetidas à cirurgia bariátrica pela técnica de Derivação Gástrica em Y de Roux (DGYR) (OP) há mais de um ano e grupo controle de 38 mulheres saudáveis pareadas po idade e condição econômica (NOP), foram avaliadas quanto ao consumo alimentar pelo registro alimenta de quatro dias não consecutivos. Adotou-se como referencial a Dietary Reference Intake. Resultados: A contribuição dos macronutrientes em relação ao valor energético apresentou distribuição aceitável para proteínas e carboidratos. Para lípides, a ingestão foi elevada nos grupos OP e NOP em 43,2 e 55,3\%, respectivamente. $\mathrm{Na}$ avaliação dos micronutrientes foi observada diferença estatisticamente significante para ferro, vitamina B12 e tiamina. Destaca-se maior risco de inadequação para zinco e cálcio, em ambo os grupos, e para ferro e vitamina Bl este achado foi observado apenas para o grupo OP. Conclusões: O consumo alimentar de mulheres submetidas à cirurgia de DGYR é muito semelhante ao de mulheres não operadas, com exceção da ingestão reduzida de ferro, vitamina B12 e tiamina, provavelmente pela dificuldade de consumir carnes e de realizar uma dieta equilibrada. Os achados reforçam a importância de orientação nutricional apropriada e de suplementação medicamentosa para esses indivíduos. 


\section{APLICAÇÃO DO SISTEMA CU(II)/CU(I)/ NEOCUPROÍNA NA AVALIAÇÃO ESPECTROFOTOMETRICA DE FÁRMACOS IN VITRO E DE POLIFENÓIS EM AMOSTRAS DE VINHO}

Autora: Gina Lee

Orefor

Defesa da Dissertação: 09/12/2011

Objetivo: Um novo método é proposto para determinação espectrofotométrica de fármacos in vitro e polifenóis totais em vinhos. O procedimento é uma modificação do método CUPRAC baseado na redução do $\mathrm{Cu}(\mathrm{lI})$ a $\mathrm{Cu}(\mathrm{l})$ pelos fármacos e polifenóis, em meio hidroetanólico $(\mathrm{pH}=7,0)$ na presença de neocuproína (2,9-dimetil-1,10-fenantrolina), resultando em complexos de $\mathrm{Cu}(1)$ com máximo de absorção em $454 \mathrm{~nm}$. Uma típica curva analítica com dipirona padrão ( $\mathrm{y}=0,08645+13803 . \mathrm{x}, \mathrm{r}=0,998 ; \mathrm{n}=5)$ mostr que a faixa linear de trabalho varia de 5,0 a 50 J.lM com limite de detecção de 4,2 J.lM. Os valores das taxa de recuperação para as amostras de dipirona em xarope, conta-gotas e injetável variaram de 95,3 a 104,1\% (valor médio de $99 \%$ ). A curva analítica com salbutamol padrão $(\mathrm{y}=0,00259+21963 . \mathrm{x}, \mathrm{r}=0,994, \mathrm{n}=5$ ) mostra que a faixa linear de trabalho varia de 2,0 a $18 \mathrm{~J} .1 \mathrm{M}$ com limite de detecção de $1,9 \mathrm{~J} .1 \mathrm{M}$. Os valore das taxas de recuperação para os comprimidos de salbutamol variaram de 91,6 a 94,7\% (valor médio de $93,6 \%)$. Os valores de absorbância obtidos para os polifenóis também foram lineares. Para ácido tânico, por exemplo, uma típica curva analítica apresenta $\mathrm{y}=0,00883+292.000$. $\mathrm{x}$ com $\mathrm{r}=0,998$ para $\mathrm{n}=6$ com concentrações de ácido tânico de 0,4 a 3,6 J.lM. O limite de detecção obtido é $0,24 \mathrm{~J} .1 \mathrm{M}$ e o desvio padrão relativo $1,2 \%(1 \mathrm{~J}, \mathrm{M}, \mathrm{n}=8)$. Foram determinados os teores de polifenol total em 14 amostras de vinhos todas essas amostras variaram de 80 a $110 \%$ (valor médio de $95 \%$ ).

\section{CARREIRA CRIMINAL, CONSUMO DE ÁLCOOL E OUTRAS DROGAS E HISTÓRIA FAMILIAR E CRIMINALIDADE ENTRE MULHERES CONDENADAS POR CRIME DE ROUBO}

Autor: Fernando Henrique Nadalini Maud

Orientador: Prof. Dr. Danilo Antonio Baltie

Defesa da Dissertação: 13/12/2011

Objetivo: $O$ presente estudo avaliou a idade de início do comportamento criminoso e a duração da carreir criminal entre mulheres que roubam. Poucas pesquisas estão disponíveis sobre os fatores relacionados carreira criminal entre mulheres sentenciadas por crimes violentos, ou mesmo não violentos. $\mathrm{O}$ objetivo desta pesquisa foi identificar os fatores relacionados ao início e a reincidência do comportament criminoso entre 175 mulheres condenadas apenas por roubo com relação ao uso de substâncias psicoativa , impulsividade, sintomas depressivos e história familiar de problemas com a justiça. Este estudo demonstro que ter um membro da família com história de condenação foi um fator positivamente associado con um início mais precoce de atividades criminosas e uma carreira criminal mais longa. O uso de droga na juventude e a gravidade do abuso de substâncias foram significativamente relacionados ao início e reincidência criminal, respectivamente. Essa constatação sugere que os filhos das apenadas poderiam ser acompanhados e auxiliados a fim de atenuar os efeitos das consequências negativas do encarceramento dos seus genitores, bem como o sistema penitenciário deveria realizar avaliações sistemáticas dos apenados e fornecer tratamento para aqueles com doenças mentais.
ANÁLISE DA CORRELAÇÃO ENTRE AS MEDIDAS DA ESPESSURA DO PROCESSO CORACOIDE E O DIÂMETRO DA CAVIDADE GLENOIDAL

Autor: Rogério Serpone Bueno Orientador: Prof. Dr. Joel Murachovsky Defesa da Dissertação: 13/12/2011

Introdução: Pacientes com diversos episódios de luxação do ombro sofrem gradualmente erosão da cartilagem e do osso da borda anterior da cavidade glenoidal (CG), com aumento da instabilidade da articulação. O tratamento desses pacientes é cirúrgico com colocação de enxerto ósseo, uma vez que o tratamento por via artroscópica da lesão de Bankart, apresenta índices de recidiva inaceitáveis. Dentre os enxertos disponíveis, o processo coracoide (PC) tem sido amplamente utilizado desde a descrição do procedimento de Latarjet. No entanto, até o presente, não está bem estabelecido qual a porcentagem de erosão da CG que pode ser reconstruída com o enxerto do PC. Objetivo: Analisar a correlação entre o PC e a CG, por meio da mensuração da espessura medial-Iateral (M-L) do PC e do diâmetro entre o

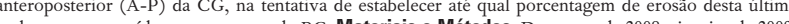
pode ser roonstifh con foram avaliadas sessenta e uma escápulas, não pareadas, de cadáveres humanos adultos. Três examinadores realizar am trés medidas independentes da maior espessura $\mathrm{M}-\mathrm{L}$ do $\mathrm{PC}$ e também da maior distância A-P da CG com paquímetro digital. Resultados: A maior espessura M-L do PC foi, em média, 14.33 \pm 1.87 milímetros. A maior distância A-P da CG foi, em média, $26,25 \pm 2,68 \mathrm{~mm}$. A correlação entre as variávei demonstrou que a espessura M-L do PC representou, em média, $54,20 \% \pm 5,46 \%$ (variando de 43 a $70 \%$ ) do maior diâmetro A-P da CG. A correlação de Spearman mostrou-se positiva e estatisticamente significante entre essas duas variáveis $(\mathrm{p}<0.001)$. O índice de Correlação Intraclasse $(\mathrm{lCC})$ intra e interobservado mostraram-se estatisticamente significantes $(\mathrm{p}<0,05)$ e com alta confiabilidade. O Teste de KolmogoróvSmimóv demonstrou distribuição normal dos valores obtidos, com nível de confiança de $95 \%$. Conclusão Existe correlação entre a espessura M-L do PC e o diâmetro A-P da CG. No tratamento dos pacientes com luxação recidivante do ombro, o PC pode ser utilizado como enxerto ósseo na reconstrução de erosões de até 54\% do diâmetro linear da CC.

\section{PERCEPÇÕES SOBRE A OBESIDADE SOB A ÓTICA DE ESTUDANTES UNIVERSITÁRIOS DA ÁREA DE SAÚDE}

Autora: Juliana Kessar Cordoni Orientadora: Profa. Dra. Ligia de Fatima Nóbrega Reato Defesa da Dissertação: 16/12/2011

Introdução: Pessoas com sobrepeso e obesidade vêm se revelando como um dado preocupante, mas não há muitos estudos sobre a visão dos profissionais de saúde no tratamento da obesidade. Objetivo: Foi realizado um estudo junto a estudantes universitários da área de saúde com foco na obesidade. Material e Metodologia: $\mathrm{O}$ método de pesquisa utilizado foi a coleta de dados e a análise quali-quantitativa. Os estudantes viram imagens da figura humana e responderam questionários. Resultados: O resultado obtido érum Concén mundo atual. Conclusão: E importante que os profissionais de saúde trabalhem seus aspectos emocionai

\section{AVALIAÇÃO DA AÇÃO DA MOMETASONA TÓPICA NOS HALOS PIGMENTARES DE MICROENXERTIA EM VITILIGO}

Autora: Karine Dantas Diógenes Saldanha

Orientador: Prof. Dr. Carlos D'A pparecida Santos Machado Filho

Defesa da Dissertação: 27/02/2012

Vitiligo é um transtorno de pigmentação frequente na população mundial. Suas modalidades de tratamento ainda oferecem resultados limitados em alguns pacientes. Nos casos de vitiligo estável clinicamente, 。 transplante de melanócitos torna-se uma opção terapêutica adicional. Existem diversas técnicas cirúrgicas no vitiligo, porém a técnica de enxertos autólogos por punch é empregada de modo fácil, rápido e com boa resposta na repigmentação. Estudou-se a ação do corticosteroide tópico mometasona sobre os halos de repigmentação após enxertos autólogos por punch em pacientes com vitiligo estável clinicamente. de repigmentação após enxertos autologos por punch em pacientes com vitiligo estável clinicamente. Entre 2009 e 2010 , 11 pacientes com vitiligo estável (sete generalizados, dois focais e dois segmentares) foram selecionados e submetidos a enxertos autólogos por punch nas máculas acrômicas. Conforme o tipo
clínico do vitiligo, os pacientes foram orientados a aplicar pomada de mometasona por 6 meses em lesões clinico do vitiligo, os pacientes foram orientados a aplicar pomada de mometasona por 6 meses em lesóes enxertadas selecionadas individualmente. No primeiro mês, a aplicação era duas vezes ao dia, e nos demais,
apenas uma vez ao dia. Foram reavaliados nos meses 1,3 e 6 após enxertos cujos halos eram fotografados apenas uma vez ao dia. Foram reavaliados nos meses 1,3 e 6 após enxertos cujos halos eram fotografados e registrados pelo software fotofinder. No fim do sexto mês, todas as áreas dos halos de repigmentação com e sem mometasona foram mensuradas e analisadas comparativamente. A mediana da área dos halos de repigmentação após os 6 meses com mometasona foi superior $\left(25,96 \mathrm{~mm}^{2}\right.$, amplitude interquartílica: $51,59)$ à mediana daqueles sem mometasona $\left(13,86 \mathrm{~mm}^{2}\right.$, amplitude interquartílica: 44,94), com diferença estatisticamente significante $(\mathrm{p}=0,026)$. Em nossa casuística, o uso da mometasona tópica determinou incremento dos halos de repigmentação após enxertia. A amplificação da amostra se faz necessária em estudos posteriores a fim de ratificar essa ação positiva da mometasona no tratamento do vitiligo estável. 